PROF. JOHANNA MYLLYHARJU (Orcid ID : 0000-0001-7772-1250)

Article type : Review Article

\title{
Prolyl and lysyl hydroxylases in collagen synthesis
}

\section{Antti M. Salo \& Johanna Myllyharju}

Oulu Center for Cell-Matrix Research, Biocenter Oulu and Faculty of Biochemistry and Molecular Medicine, University of Oulu, Oulu, Finland.

Corresponding author: Johanna Myllyharju, Faculty of Biochemistry and Molecular Medicine, PO Box 5400 (Street address Aapistie 7A), Fl-90014, University of Oulu, Oulu, Finland. Email: johanna.myllyharju@oulu.fi

Conflict of interest statement: No conflict of interest.

Author contribution statement: AMS and JM wrote the paper and have read and approved the final manuscript.

Data availability statement: Not applicable (review article).

Funding information: This work was supported by the Academy of Finland Project Grant 296498, the S. Jusélius Foundation and the Jane and Aatos Erkko Foundation to JM.

This article has been accepted for publication and undergone full peer review but has not been through the copyediting, typesetting, pagination and proofreading process, which may lead to differences between this version and the Version of Record. Please cite this article as doi: 10.1111/EXD.14197

This article is protected by copyright. All rights reserved 


\section{Abstract}

Collagens are the most abundant proteins in the extracellular matrix. They provide a framework to build organs and tissues and give structural support to make them resistant to mechanical load and forces. Several intra- and extracellular modifications are needed to make functional collagen molecules, intracellular post-translational modifications of proline and lysine residues having key roles in this. In this article we provide a review on the enzymes responsible for the proline and lysine modifications, i.e. collagen prolyl 4-hydroxylases, 3-hydroxylases and lysyl hydroxylases, and discuss their biological functions and involvement in diseases.

Keywords: Collagen, Extracellular matrix, Animal model, Human model 


\section{Introduction to collagens and their biosynthesis}

Collagens are the most abundant proteins in the extracellular matrix (ECM). They provide a framework to build organs and tissues and give structural support to make them resistant to mechanical load and forces. Collagens have also many other key roles for example in barrier function, cell-cell interactions, differentiation, signaling, adhesion and migration. Disruption of collagen molecules themselves or their biosynthesis can lead to defects in these functions manifested as various connective tissue diseases and defects. The collagen family of proteins comprises 28 different collagen types that are sub-grouped according to their supramolecular properties. In addition, more than a dozen soluble extracellular proteins such as adiponectin and C1q have collagen-like triple-helical domains. For previous reviews on collagens, see for example (1-8).

Collagen molecules are composed of three $\alpha$ chains that have a collagenous amino acid sequence composed of -Gly-X-Y- repeats and are folded into a triple helix in a defined chain registry. The smallest amino acid glycine as every third amino acid allows the triple helix formation. $X$ and $Y$ position amino acids have their side chains pointing outwards from the helix and they are often proline and 4-hydroxyproline, respectively $(5,8-10)$. Collagen molecules are either homotrimers or heterotrimers depending on the collagen type. Correct chain selection for the triple helix assembly is governed by C-terminal noncollagenous extensions that are either cleaved later ( $C$ propeptides of fibrillar collagens) or retained in the final superstructure (for example type IV collagen) (11-13). Mature collagen molecules typically contain also non-collagenous domains. In fibril-forming collagens these are limited to short non-collagenous telopeptides at both ends that contain sites for intermolecular cross-links, while other collagen types may have multiple interrupting non-collagenous domains with various functions $(2,5,14)$.

Here we will introduce shortly only a few collagen types. The most abundant protein in the human body is type I collagen known mainly for its structural role. It is the main component of collagen fibrils that occupy large volumes in the dermis, bone, tendon, and cornea, for example. Collagen fibrils are typically heteropolymers and type I collagen fibrils contain also smaller amounts for example type III and V collagens. Type II collagen is the main constituent in cartilage, and type II collagen fibrils contain also type IX and XI collagens. Collagen fibrils are highly organized structures with the constituent collagen molecules staggered longitudinally and laterally in a specific manner to allow the assembly of long fibrils. Type IV collagen forms network-like supramolecular structures and is one of the key components of basement membranes (15). Type VII collagen forms anchoring fibrils that are crucial for the structural integrity of the skin (16).

This article is protected by copyright. All rights reserved 
Several intra- and extracellular modifications are needed to make functional collagen molecules, intracellular post-translational modifications of proline and lysine residues having key roles in this. These amino acids are enzymatically modified to 4-hydroxyproline (4Hyp), 3-hydroxyproline (3Hyp) and hydroxylysine ( $\mathrm{Hyl}$ ) by collagen prolyl 4-hydroxylases ( $\mathrm{P} 4 \mathrm{Hs})$, prolyl 3-hydroxylases (P3Hs) and lysyl hydroxylases (LHs), respectively (Fig. 1) (8,17-19). The Hyl residues can be futher glycosylated to form galactosyl-Hyl and glucosylgalactosyl-Hyl residues $(20,21)$. These reactions take place in the endoplasmic reticulum (ER) before folding of the collagen triple helix. In addition to these, several other enzymes and proteins are needed in collagen biosynthesis. These include for example peptidyl prolyl cis-trans isomerases (PPlases) that are needed to convert all prolines to the trans conformation in a reaction that is also a rate-limiting step in collagen biosynthesis.

Upon the completion of the intracellular modifications and folding of the triple helix, the collagen molecules are secreted into the extracellular space, where they assemble into larger superstructures for their ultimate structure and function $(5,8,22,23)$. In case of fibril-forming collagens, cleavage of the $\mathrm{N}$ - and C-terminal propeptides by specific proteases precedes the self-assembly of the fibrils $(5,24,25)$. Many of the superstructures are further strengthened by crosslinking initiated by lysyl oxidase (LOX) that catalyzes aldehyde formation of certain lysine and Hyl residues $(26,27)$.

The collagen prolyl and lysyl hydroxylases require molecular oxygen $\left(\mathrm{O}_{2}\right), 2$-oxoglutarate (2OG), $\mathrm{Fe}^{2+}$ and ascorbate in the reaction. They belong to a large family of $20 \mathrm{G}$ dependent dioxygenases and their catalytic properties have been reviewed extensively $(18,28)$ and will not be discussed here further. As the hydroxylations have a profound effect in collagen synthesis, the potential of the responsible hydroxylases as antifibrotic therapy targets is apparent. No collagen hydroxylase inhibitor is in clinical use, however, although many competitive inhibitors with respect to iron or $2 \mathrm{OG}$ are known especially for collagen $\mathrm{P} 4 \mathrm{H}$ $(1,19,29,30)$. 4Hyp was for a long time believed to exist only in collagens and collagen-like proteins, but in 2001 it was discovered to have a novel key regulatory role in the oxygen-dependent degradation of the hypoxia-inducible factor (HIF) (31,32). A separate P4H family was rapidly discovered to be responsible for the hydroxylation of HIF (33-35) and the HIF P4Hs were found to act as very efficient oxygen sensors (3638). These mechanistic discoveries on the regulation of the hypoxia response were awarded the Nobel prize in physiology or medicine in 2019 (39). Prior knowledge of collagen P4H inhibitors enabled rapid analyses of the HIF P4Hs revealing that distinct differences existed in the inhibitory properties between the two P4H families $(37,40-43)$. Several HIF P4H inhibitors are currently in clinical trials (44-46) to treat severe anemia of chronic kidney diseases and the first one (Roxadustat, FibroGen Inc.) was approved in China in 2018, Japan in 2019 and the approval processes in the USA and Europe are ongoing. 
Next, we will shortly review the current knowledge of the key collagen hydroxylases separately. The main features of human mutations and transgenic mouse phenotypes in the collagen proline and lysine modification pathways are summarized in Table 1.

\section{Prolyl 4-hydroxylation}

4Hyp is generated in the collagen polypeptides in -X-Pro-Gly- sequences. The thermal stability of the collagen triple helix is critically dependent on 4Hyp residues and essentially all prolines in the $Y$ positions of the -X-Y-Gly- repeats need to be hydroxylated in order to reach the correct triple-helical conformation (Fig. 2) (47) . For example, the $\alpha 1$ (I) chain contains about 100 Y position 4 Hyp residues per 1000 amino acids (48-50). The 4Hyp residues stabilize the triple helix via a stereoelectronic effect (9). Furthermore, the 4 Hyp residues have a role in the binding of the cell adhesion receptors integrins and discoidin domain receptors $(7,51-53)$.

The enzyme catalyzing the formation of $4 \mathrm{Hyp}$ residues in collagens is collagen $\mathrm{P} 4 \mathrm{H}(1,18,29,54)$. This enzyme is an $\alpha_{2} \beta_{2}$ tetramer that consists of two catalytic $\alpha$ subunits and two $\beta$ subunits that are identical to the protein disulfide isomerase (PDI) (55). Vertebrate collagen $\mathrm{P} 4 \mathrm{H}$ has three isoenzymes, collagen P4Hs I, II and III, that differ in their catalytic $\alpha$ subunits that are encoded by the genes P4HA1, P4HA2 and P4HA3 (56-61). The catalytic $\alpha$ subunits are themselves highly insoluble and association with the PDI/ $\beta$ subunit is required for the formation of an active collagen $\mathrm{P} 4 \mathrm{H}$ tetramer that is retained in the ER via the KDEL retention signal of the PDI/ $\beta$ subunit (62-64). Although the $\alpha$ subunit contains essential intramolecular disulfide bonds, the PDI activity of the $\beta$ subunit is not required for correct assembly and activity of the collagen $\mathrm{P} 4 \mathrm{H}$ tetramer $(63,65,66)$. However, another related chaperone, ERp60, cannot substitute for PDI as the collagen $\mathrm{P} 4 \mathrm{H} \beta$ subunit (67).

A high-resolution crystal structure is not yet available for the collagen $\mathrm{P} 4 \mathrm{H}$ tetramer or for its catalytic $\alpha$ subunit due to the insolubility of the latter. However, a small-angle X-ray scattering (SAXS) model for the entire tetramer (68) as well as high-resolution crystal structures of two of the three functional domains of the $\alpha$ subunit, the $\mathrm{N}$-terminal dimerization domain and the central peptide substrate binding domain (6871), and the PDI (72) have been solved. Based on the SAXS model the collagen P4H tetramer is an extended symmetric molecule with two lobes and a total length of $290 \AA$. The two lobes are dimerized via the N-terminal domains of the $\alpha$ subunits and this dimer interface forms the "waist" of the elongated tetramer. The lobes that protrude out from the waist are formed by the peptide substrate binding domain

This article is protected by copyright. All rights reserved 
and the catalytic domain of the $\alpha$ subunit that make a complex with the PDI/ $\beta$ subunit, the latter being located at the far ends of the elongated tetramer (Fig. 1). Although the exact structure of the catalytic domain and hence the catalytic site of the $\alpha$ subunit is not yet known, it is likely to adopt the conserved distorted double-stranded $\beta$-helix, also known as a jelly-roll, core fold found in all 20G-dependent dioxygenase structures solved so far ensuring correct positioning of the conserved catalytically critical iron and $20 \mathrm{G}$ binding residues $(73,74)$. This is also supported by the high-resolution crystal structures of two related P4Hs, a HIF P4H and an algal P4H (75-78).

Due to the central role of collagen P4Hs in collagen synthesis they have long been considered as potential targets for antifibrotic drugs, another interesting anti-fibrotic target among the collagen hydroxylases being LH2 (see below) $(1,29,30)$. Expression of the collagen hydroxylases, as well as expression of LOX, are induced in hypoxia (79-83), which is a prominent feature of fibrosis. Furthermore, hypoxic induction of the collagen hydroxylases and LOX has been implicated in cancer metastasis (84-86) and a large number of publications is accumulating on their potential use as therapeutic, diagnostic and prognostic targets in various cancers.

\section{Genetic disorders of prolyl 4-hydroxylases}

Until now only a single human patient with a connective tissue disease caused by P4HA1 mutations has been identified (87). The disease manifests as early-onset joint hypermobility, joint contractures, muscle weakness, bone dysplasia, high myopia and delayed motor milestones with improvement of motor function over time. The patient was found to be a compound heterozygote for frameshift and splice site mutations in the P4HA1 gene leading to reduced P4HA1 protein level, collagen $\mathrm{P} 4 \mathrm{H}$ activity and thermal stability of collagen. P4HA2 mutations have been identified and associated with nonsyndromic high myopia $(88,89)$. Heterozygous $P 4 H B$ (PDI) mutations have been identified in Cole-Carpenter syndrome with bone fragility and other symptoms (Balasubramanian et al. 2018, Ouyang \& Yang. 2017, Rauch et al. 2015).

\section{Prolyl 4-hydroxylase mouse models}

The collagen P4H isoenzyme I is the major isoform in most tissues studied $(57,90,91)$. In line with this, P4ha1 knockout (KO) mice turned out to be embryonic lethal between 10.5 and 11.5 days post coitum (dpc) (92). The total collagen P4H activity in the P4ha1 KO embryos was reduced by about $80 \%$. The P4ha1

This article is protected by copyright. All rights reserved 
KO embryos developed normally until $9 \mathrm{dpc}$ followed by severe retardation in the development and at $10.5 \mathrm{dpc}$ the embryos were pale, extremely fragile and markedly smaller than their wild-type littermates. The capillary walls were found to be disrupted in the P4ha1 KO embryos because of inability to synthesize and deposit collagen IV into the basement membranes. Highest expression of P4HA2 is detected in chondrocytes, but P4ha2 KO mice do not manifest any overt skeletal or other defects (93). However,

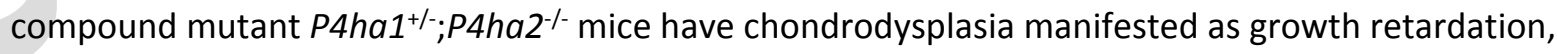
moderate but significant shortening of long bones and development of kyphosis at older age. Shortening of the long bones in the compound mutant mice was found to be caused by cell death resulting (81) in transient hypocellularity in the innermost region of the developing growth plates in the middle of the proliferative and hypertrophic zones from $17.5 \mathrm{dpc}$ onwards until postnatal day 7 . The collagen matrix was abnormally organized and significantly softer in the mutant growth plates, the 4Hyp content was reduced and this was associated with a lower melting temperature of type II collagen isolated from the mutant growth plates.

The fact that the most dramatic effects in the $P 4 h a 1^{+-} ; P 4 h a 2^{-/-}$mice were observed in the central region of the growth plates is particularly interesting because this location is extremely hypoxic and local activation of the hypoxia-inducible factor HIF and the hypoxia response pathway has been shown to play a critical role in growth plate development $(94,95)$. Like other $20 \mathrm{G}$ dependent dioxygenases, collagen P4Hs require molecular oxygen in the reaction and it has been shown that hypoxia-driven upregulation of collagen $\mathrm{P} 4 \mathrm{Hs}$ in chondrocytes is necessary to ensure sufficient collagen hydroxylation capacity in a hypoxic environment $(79,81)$. Therefore, it is likely that the growth plate is a particularly sensitive tissue for any deviations in collagen $\mathrm{P} 4 \mathrm{H}$ availability and activity. This is supported by a recent study reporting a highly interesting metabolic link between hypoxia, collagen $\mathrm{P} 4 \mathrm{H}$ and collagen synthesis in the growth plate (96). In this study it was shown that extended HIF signaling in growth plate chondrocytes leads to impaired longitudinal bone growth and increased trabecular bone mass by interfering with cellular bioenergetics and biosynthesis. The HIF-mediated metabolic reprogramming involved reduced oxidation of glucose and fatty acids, but not glutamine, resulting in an energy deficit that limited chondrocyte proliferation, activated the unfolded protein response and reduced collagen synthesis. On the other hand, the level of 20G, a necessary component of the collagen $\mathrm{P} 4 \mathrm{H}$ reaction, was increased via the enhanced glutamine flux. This resulted in increased proline and lysine hydroxylation of collagen, a more protease resistant cartilaginous matrix and increased bone mass.

This article is protected by copyright. All rights reserved 


\section{Prolyl 3-hydroxylation}

The exact molecular role of $3 \mathrm{Hyp}$ in collagen is still not clearly understood, but its critical importance is seen by the fact that its absence in type I collagen is associated with severe Osteogenesis imperfecta $(97,98)$. It has been suggested that 3 Hyp plays a role in type I collagen fibril assembly $(99,100)$ and interactions of type IV collagen with other proteins (101). The substrate proline of P3H is in the sequence Pro-4Hyp-Gly- $(102,103)$, but not all such potential sites are hydroxylated, and consequently fibrillar collagens have relatively few 3 Hyp residues. The X-position Pro(986) of the $\alpha 1$ chain of type I collagen, $\alpha 1(\mathrm{I})$, and the corresponding Pro residues in the $\alpha 1(\mathrm{II})$ and $\alpha 2(\mathrm{~V})$ chains are virtually fully 3-hydroxylated. Partial hydroxylation of a few other sites Pro(944) in $\alpha 1(\mathrm{II})$ and $\alpha 2(\mathrm{~V}), \operatorname{Pro}(707)$ in $\alpha 2(\mathrm{I})$ and $\alpha 2(\mathrm{~V})$, and Pro(470) in $\alpha 2(V)$ has also been identified. In contrast, human and bovine type III collagen does not seem to have any 3 Hyp residues (100). It is noteworthy that $3 \mathrm{Hyp}$ is not entirely restricted to these sites as other sites, with likely a lower 3 Hyp occupancy, have been detected elsewhere in the $\alpha 1(V)$ chain (104). In contrast to fibrillar collagens, type IV collagen has a higher 3Hyp content that is in the range of about 15 residues in the $\alpha 1$ (IV) chain $(105,106)$. Furthermore, there may also be tissue specific differences as type I collagen isolated from the tendon has about three 3Hyp residues in the C-terminal -Gly-Pro-4Hyp- repeats in addition to the site Pro(986), while only one 3Hyp residue at Pro(986) is found in the skin in this region $(107,108)$.

There are three $\mathrm{P} 3 \mathrm{H}$ s (EC 1.14.11.7) in vertebrates, $\mathrm{P} 3 \mathrm{H} 1, \mathrm{P} 3 \mathrm{H} 2$ and $\mathrm{P} 3 \mathrm{H} 3$ encoded by LEPRE1, LEPREL1 and LEPREL2, respectively (109). Two additional members of this Leprecan family of proteins are the nonenzymatic cartilage-associated protein CRTAP and SC65 $(98,110)$. P3H1 forms a complex with CRTAP and the peptidyl-prolyl cis-trans isomerase cyclophilin B (CYPB) with 1:1:1 stoichiometry (109). The complex contains $\mathrm{P} 3 \mathrm{H}$ and peptidyl-prolyl cis-trans isomerase activities and in addition has chaperone functions $(109,111)$. The complex components P3H1 and CRTAP stabilize each other and loss of either one will lead to loss of the other as well, while CYPB levels are not affected (112).

The function of $\mathrm{P} 3 \mathrm{H} 2$ has been linked to basement membranes. It is expressed in tissues that are rich in basement membranes, such as the kidney (113-115), and recombinant P3H2 hydroxylates more effectively peptides representing type IV collagen hydroxylation sites than type I collagen sites (113). However, it may also hydroxylate other collagen types (114).

P3H3 function is largely unknown and expression of recombinant active $\mathrm{P} 3 \mathrm{H} 3$ has so far not been successful (Tiainen et al. 2008). However, when deleted in mouse, no effect on prolyl 3-hydroxylation was found, but instead a lysine underhydroxylation was observed (116). Interestingly, and similarly to P3H3, 
lysine underhydroxylation is observed also when SC65, non-enzymatic member of the same protein family, is absent (116). Both P3H3 and SC65 are reported to be in the same ER complex with LH1 and potentially also with CYPB (117). In line with this, recent reports suggest that also CYPB modulates lysine modifications $(118,119)$.

\section{Genetic disorders of prolyl 3-hydroxylases}

Osteogenesis imperfecta $(\mathrm{OI})$ is characterized by skeletal deformities and bone fragility. Ol affects one in 15000-20000 births and autosomal dominant COL1A1 and COL1A2 mutations underlie most of the cases. Mutations in any of the components of the P3H1:CRTAP:CYBP complex can lead to recessive OI (120-122). P3H1 and CRTAP mutations that cause severe to lethal type VIII and VII OI, respectively, lead also to collagen overmodification, i.e. increased lysine hydroxylation and glycosylation, due to delays in collagen folding (123). The type IX OI caused by CYPB mutations can be either moderate or lethal and a distinctive feature in comparison to OI caused by P3H1 or CRTAP mutations is that the CYPB patients do not have rhizomelia (120-122). P3H2 mutations have been shown to cause high myopia and certain other eye symptoms (124-128). No human P3H3 mutations have so far been identified.

\section{Prolyl 3-hydroxylase mouse models}

Several P3H1:CRTAP:CYPB OI mouse models have been generated. The P3h1 KO mice have abnormal collagen fibril assembly in many collagen I rich tissues including bone, tendon and skin. The P3h1 KO mice are also smaller and have various bone defects including reduced bone mass and strength and bone matrix hypermineralization $(129,130)$. Similarly, Crtap KO mice also exhibit OI-like bone defects such as shortening of the long bones, severe osteopenia and high bone matrix mineralization, and in addition have connective tissue defects in many tissues other than bone (130-132). Likewise, inactivation of Cypb in mouse leads to small body size and an OI-like phenotype without rhizomelia $(133,134)$. Cells derived from the Cypb KO mice showed greatly reduced P3H1 levels whereas CRTAP was unaffected (134). Lack of CYBP slowed down type I collagen folding and in addition to reduction in prolyl 3-hydroxylation, tissueand site-specific alterations were observed in lysyl hydroxylation and glycosylation of type I collagen, as well as fibril assembly and crosslinking $(118,119,133)$. These mouse models are highly valuable tools for mechanistic studies of OI types VII, VIII and IX. Regarding the role of the lack of $3 \mathrm{Hyp}$ in the type I collagen position Pro(986) and development of OI, an elegant study was recently performed with a targeted

This article is protected by copyright. All rights reserved 
mutant mouse model with a $\alpha 1$ (I)Pro986Ala substitution (135). These mice did not manifest the OI disease phenotype, but had abnormalities in the structural organization of collagen fibrils and crosslinking chemistry. These data may indicate that inactivation of the chaperone functions of the P3H1:CRTAP:CYPB complex has a more direct role in OI than lack of the 3Hyp in position Pro(986).

At least two P3h2 KO mouse models are currently available, interestingly with very different phenotypes, perhaps due to different targeting strategies. One is embryonically lethal early in development before 8.5 $\mathrm{dpc}(136)$, while the other is indistinguishable from the wild-type littermates but exhibits severe reduction in prolyl 3-hydroxylation in type I and IV collagen in the eye (114). The lethal phenotype was found to result from the interaction of 3 Hyp-depleted type IV collagen with the maternal platelet-specific glycoprotein VI (GPVI), which leads to maternal platelet aggregation, blood thrombosis and death of the embryo (136).

P3h3 KO mice are viable and have no apparent abnormalities in skeletal development and no effect on collagen prolyl 3-hydroxylation was detected. Instead, lysine residues were underhydroxylated and collagen crosslink chemistry was altered (116). Thus, lack of P3H3 seems to have an effect on LH activity, supported by the finding that P3H3 forms a complex with SC65 and potentially LH1 and CYPB (Heard et al. 2016). Likewise, loss of Sc65 in mouse did not lead to any macroscopic or patterning defects in skeletal structures, although progressive osteopenia that affects both cortical and trabecular bone was observed and found to be due to increased bone resorption (137). The Sc65 KO mice also had no reduction in collagen prolyl 3-hydroxylation, but exhibited lysine underhydroxylation (116). Both P3h3 and Sc65 null mice show also some evidence of skin fragility $(116,117)$. As the phenotype of the P3h3 (and Sc65) KO mice resembles that of Plod1 (LH1) KO mice (138), human P3H3 mutations could potentially cause a similar syndrome as PLOD1 mutations, namely the kyphoscoliotic Ehlers-Danlos syndrome (kEDS) (see below).

\section{Lysyl hydroxylation and hydroxylysine glycosylation}

The biological role of $\mathrm{Hyl}$ residues is to participate in collagen cross-linking via covalent attachments between neighbouring collagen molecules and determine the chemical nature of the cross-links (Fig. 3). LOX (EC 1.4.3.13) catalyzes the last enzymatic reaction in the cross-link formation. In fibrillar collagens the telopeptide lysine or Hyl is deaminated by LOX producing the reactive aldehydes allysine or hydroxyallysine, respectively. This then interacts with a lysine, Hyl or histidine in the triple-helical region. 
For example, type I collagen has cross-linking sites at both telopeptides and at the helical region near or at residues 87 or 930 . The hydroxylysylpyridinoline (HP) cross-link is formed when two telopeptidyl hydroxyallysine residues bind with Hyl in the triple helix (Fig. 3). HP cross-links are present in most connective tissues such as bone, cartilage and tendon, but are absent in skin and cornea. Lysylpyridinoline (LP) cross-link is made when two telopeptidyl hydroxyallysines bind with a Lys in the triple helix (Fig. 3).

For reviews, see (139-142). Besides the role in cross-link formation, Hyl residues serve as attachment sites for galactosyl and glucosylgalactosyl moieties (Figs. 1 and 3) $(20,21)$.

The enzyme catalyzing lysyl hydroxylation is LH (EC 1.14.11.4) that has three isoenzymes in vertebrates, LH1, LH2 and LH3. They are encoded by the genes PLOD1, PLOD2 and PLOD3, respectively (143-147). The consensus sequence for lysyl hydroxylation is -X-Lys-Gly-, although telopeptide lysyl hydroxylation occurs in -X-Lys-Ala- and -X-Lys-Ser- sequences. The Hyl content (5-70 Hyl/1000 amino acids) varies between collagen types and between different tissues $(139,142)$. A number of evidence including the recent high resolution crystal structure of LH3 (148) indicate that dimerization is needed for LH function (148-152). The LH isoenzymes all have at least partially different functions. LH1 primarily hydroxylates lysines that reside in the helical parts of collagen molecules (19). In contrast, LH2 is evidently the only one responsible for hydroxylation of lysines in the telopeptides (153-155). LH2 has two splice variants, LH2a (short form) and LH2b (long form) that has an extra 63bp exon 13A between exons 13 and 14 (156), the variant LH2b being the one involved in the formation of pyridinoline cross-links $(157,158)$. In addition to LH activity, LH3 has been shown to possess collagen glycosyltransferase activity (159-161)

Certain Hyl residues in collagen molecules are enzymatically glycosylated. Galactose is added via a $\beta$-glycosidic bond to the hydroxy group of $\mathrm{Hyl}$ to form galactosyl-Hyl. Some of these are further modified by addition of glucose using an $\alpha$-glycosidic bond between the sugar molecules to form glucosylgalactosylHyl residues. These modifications are catalyzed by a Hyl galactosyltransferase (GT) (EC 2.4.1.50) and galactosyl-Hyl glucosyltransferase (GGT) (EC 2.4.1.66), respectively. Surprisingly, the enzyme responsible for collagen GGT activity was identified to be LH3 (159). Later it was found to possess also GT activity but at lower levels $(160,161)$. More recent data suggest that the de facto collagen GT enzymes are COLGALT1 (GLT25D1) and COLGALT2 (GLT25D2) that have strong GT activity (162) and link to reduced galactosyl-Hyl in type I collagen (163). The role of LH activity in LH3 is not well understood and it has been established that the LH3 collagen glycosyltransferase activity, especially GGT, is its most important function for many collagens, including types I and IV $(159,164-166)$. Hyl glycosylation is reasonably high especially in type IV and VI collagens that have been shown to require LH3 dependent glycosylation for secretion and assembly (167). The glucosylation sites have been mapped in human and mouse type IV collagen and for 
example the mouse $\alpha 1$ (IV) chain has 39 glycosylated $\mathrm{Hyl}$ residues compared to 10 non-glycosylated $\mathrm{Hyl}$ residues, and $1484 \mathrm{Hyp}$ and seven 3 Hyp residues (105). The study also revealed both heterogeneity and conservation in individual glycosylation sites.

Similarly to prolyl hydroxylases, LHs are also ER enzymes with the exception that LH3 is, in addition to its ER localization, also found in the extracellular space (168) and its regulated trafficking is required for collagen homeostasis (169). LHs have no classical ER localization sequence such as the KDEL motif. LH1 has been suggested to attach to the ER via a C-terminal region of the enzyme that is predicted to adopt an extended loop conformation (170). The crystal structure of LH3, first of any collagen prolyl or lysyl hydroxylase, will facilitate studies of the molecular mechanisms involved in the LH, GT and GGT activities of this enzyme in the future (148) and has already enabled the development of an online tool for visualization of the molecular level effects of LH mutations (171).

An increasing amount of evidence suggests that LHs are part of larger complexes with chaperones and other proteins $(119,172,173)$ potentially providing an intricate link to effects beyond lysine modifications. In line with this, chaperone and enzyme deficiencies can phenocopy each other as seen with LH1 and FKBP22 and with LH2 and FKBP65 $(174,175)$.

\section{Genetic disorders of lysyl hydroxylases and collagen glycosyltransferases}

Kyphoscoliotic Ehlers-Danlos syndrome (kEDS) is a generalized connective tissue disorder caused by mutations in PLOD1. The disorder is autosomal recessive and affects many tissues and exhibits for example muscular hypotonia, early-onset kyphoscoliosis, joint hypermobility, skin hyperelasticity and ocular abnormalities (176). The primary reason for the disease is reduced lysyl hydroxylation of the lysines in the triple-helical region (177). Urinary HP:LP ratio is used in diagnostics as HP cross-links are reduced and LP is elevated (Fig. 3) (177,178). Nevo syndrome patients with clinical features similar to kEDS were also found to have PLOD1 mutations and thus this syndrome is actually allelic to kEDS (179). Interestingly, kEDS with a somewhat wider spectrum of clinical phenotypes can also be caused by mutations in FKBP14 $(175,180)$ that encodes FKBP22, which belongs to the FK506 binding protein (FKBP)-family of PPlases.

Bruck syndrome (BS) is an Ol-like disorder with bone fragility and joint contractures. In BS, the telopeptides of type I collagen are underhydroxylated, in contrast to the helical lysines that are normally modified (Fig. 3) (181). BS type 2 is caused by mutations in PLOD2 (155,181-183). Interestingly, BS can also be caused by mutations in FKBP10 that encodes the PPlase FKBP65 (174). This genetic form of the

This article is protected by copyright. All rights reserved 
disorder is called BS type I and it is clinically similar to BS type 2 (155). The molecular basis that underlies the similarity between the BS types 1 and 2 is that FKBP65 is needed for dimerization of LH2 (151). In addition to BS type 1, FKBP10 mutations can also cause OI (BS minus contractures) and the Kuskokwim syndrome that is a congenital contracture syndrome (184).

First human mutations in PLOD3 were described in 2008 in a compound heterozygous patient with congenital malformations that severely affect many tissues and organs and share features of several collagen disorders (185). A decade later several other patients were identified (186-188) with different PLOD3 mutations but similar features affecting many tissues.

\section{Lysyl hydroxylase and collagen glycosyltransferase mouse models}

Targeted inactivation of Plod1 in mouse is a model for kEDS (138). The Plod1 KO mice are flaccid and have gait abnormalities and increased risk of aortic ruptures due to degenerative changes in the aortic walls. Biochemical analyses revealed reduced Hyl content in all tissues studied, the largest reduction in $\mathrm{Hyl}$ detected in the skin, $22 \%$ of the wild-type level. Similarly, HP cross-links were decreased and LP increased in all tissues to different levels. Interestingly, the total cross-link amount was increased evidently due to an overall increase in LP cross-links (138). Plod2 KO mice are embryonic lethal and die after $10.5 \mathrm{dpc}$ $(189,190)$. In light of this, recombinant LH2 polypeptides harboring the human PLOD2 mutations found in BS type 2 patients were found to have residual LH2 activity, which may be critical for the survival of the patients (183). Another BS mouse model, Fkbp10 KO, displays tissue fragility, growth delay and the mice do not survive birth (191). Deletion of $F k b p 10$ in osteoblasts produces a mouse with reduction in collagen crosslinking and a bone phenotype that is less severe than BS type I (192). Plod3 KO mice are embryonically lethal at $9.5 \mathrm{dpc}$ and show major basement membrane defects with abnormal type IV collagen deposition and growth retardation $(164,166)$. Hypomorphic Plod3 mice that have $11-20 \%$ remaining GGT activity show a milder phenotype than the full KOs. They exhibit fragmentation of the basement membranes and delayed lethality between 9.5 and $14.5 \mathrm{dpc}$ with correlation between GGT activity and survival. Mice without the LH activity of LH3, but with normal GGT activity, developed normally further pinpointing the essential nature of the GGT activity of LH3 (164). Collagen galactosyltransferase ColGalT1 mutant mice show skeletal and muscular defects and exhibit intracellular collagen IV accumulation (193). ColGalT2 KO mice have altered CD4 ${ }^{+} \mathrm{T}$ cells and response to experimental liver injury (194).

This article is protected by copyright. All rights reserved 


\section{References}

1 Myllyharju J. Prolyl 4-hydroxylases, key enzymes in the synthesis of collagens and regulation of the response to hypoxia, and their roles as treatment targets. Ann Med 2008: 40: 402-417.

2 Ricard-Blum S. The collagen family. Cold Spring Harb Perspect Biol 2011: 3: a004978.

3 Brodsky B, Persikov A V. Molecular structure of the collagen triple helix. Adv Protein Chem 2005: 70: 301-339.

4 Chen A, Fertala A, Abboud J et al. The molecular basis of genetic collagen disorders and its clinical relevance. J Bone Joint Surg Am 2018: 100: 976-986.

5 Holmes D F, Lu Y, Starborg T et al. Collagen fibril assembly and function. Curr Top Dev Biol 2018: 130: 107-142.

6 Bretaud S, Nauroy P, Malbouyres M et al. Fishing for collagen function: About development, regeneration and disease. Semin Cell Dev Biol 2019: 89: 100-108.

7 Rappu P, Salo A M, Myllyharju J et al. Role of prolyl hydroxylation in the molecular interactions of collagens. Essays Biochem 2019: 63: 325-335.

8 Myllyharju J, Kivirikko K I. Collagens, modifying enzymes and their mutations in humans, flies and worms. Trends Genet 2004: 20: 33-43.

9 Shoulders M D, Raines R T. Collagen structure and stability. Annu Rev Biochem 2009: 78: 929-958.

10 Fidler A L, Boudko S P, Rokas A et al. The triple helix of collagens - an ancient protein structure that enabled animal multicellularity and tissue evolution. J Cell Sci 2018: 131: 10.1242/jcs.203950.

11 Sharma U, Carrique L, Vadon-Le Goff S et al. Structural basis of homo- and heterotrimerization of collagen I. Nat Commun 2017: 8: 14671.

12 Boudko S P, Engel J, Bächinger H P. The crucial role of trimerization domains in collagen folding. Int J Biochem Cell Biol 2012: 44: 21-32.

This article is protected by copyright. All rights reserved 
13 Khoshnoodi J, Cartailler J P, Alvares K et al. Molecular recognition in the assembly of collagens: terminal noncollagenous domains are key recognition modules in the formation of triple helical protomers. J Biol Chem 2006: 281: 38117-38121.

14 Izzi V, Heljasvaara R, Heikkinen A et al. Exploring the roles of MACIT and multiplexin collagens in stem cells and cancer. Semin Cancer Biol 2020: 62: 134-148.

15 Brown K L, Cummings C F, Vanacore R M et al. Building collagen IV smart scaffolds on the outside of cells. Protein Sci 2017: 26: 2151-2161.

16 Nyström A, Bruckner-Tuderman L. Matrix molecules and skin biology. Semin Cell Dev Biol 2019: 89: 136-146.

17 Ishikawa Y, Bächinger H P. A molecular ensemble in the rER for procollagen maturation. Biochim Biophys Acta 2013: 1833: 2479-2491.

18 Myllyharju J. Collagen Hydroxylases. In: Schofield C J, Hausinger R P, eds. 2-Oxoglutarate-Dependent Oxygenases, The Royal Society of Chemistry, 2015: 149-168.

19 Kivirikko K I, Myllylä R. Posttranslational enzymes in the biosynthesis of collagen: intracellular enzymes. Methods Enzymol 1982: 82 Pt A: 245-304.

20 Hennet T. Collagen glycosylation. Curr Opin Struct Biol 2019: 56: 131-138.

21 Kivirikko K I, Myllylä R. Collagen glycosyltransferases. Int Rev Connect Tissue Res 1979: 8: 23-72.

22 Ishikawa Y, Boudko S, Bächinger H P. Ziploc-ing the structure: Triple helix formation is coordinated by rough endoplasmic reticulum resident PPlases. Biochim Biophys Acta 2015: 1850: 1983-1993.

23 Malhotra V, ErImann P. The pathway of collagen secretion. Annu Rev Cell Dev Biol 2015: 31: 109-124.

24 Canty-Laird E G, Lu Y, Kadler K E. Stepwise proteolytic activation of type I procollagen to collagen within the secretory pathway of tendon fibroblasts in situ. Biochem J 2012: 441: 707-717.

25 Hulmes D J S. Roles of the procollagen C-propeptides in health and disease. Essays Biochem 2019: 63: 313-323.

This article is protected by copyright. All rights reserved 
26 Trackman P C. Lysyl oxidase isoforms and potential therapeutic opportunities for fibrosis and cancer. Expert Opin Ther Targets 2016: 20: 935-945.

27 Vallet S D, Ricard-Blum S. Lysyl oxidases: from enzyme activity to extracellular matrix cross-links. Essays Biochem 2019: 63: 349-364.

28 Kivirikko K I, Myllylä R, Pihlajaniemi T. Hydroxylation of proline and lysine residues in collagens and other animal and plant proteins. In: Harding J J, Crabbe M J C, eds. Post-translational modifications of proteins, CRC Press, 1991: 1-51.

29 Vasta J D, Raines R T. Collagen prolyl 4-hydroxylase as a therapeutic target. J Med Chem 2018: 61: 10403-10411.

30 Piersma B, Bank R A. Collagen cross-linking mediated by lysyl hydroxylase 2: an enzymatic battlefield to combat fibrosis. Essays Biochem 2019: 63: 377-387.

31 Jaakkola P, Mole D R, Tian Y M et al. Targeting of HIF- $\alpha$ to the von Hippel-Lindau ubiquitylation complex by $\mathrm{O}_{2}$-regulated prolyl hydroxylation. Science 2001: 292: 468-472.

32 Ivan $\mathrm{M}$, Kondo K, Yang $\mathrm{H}$ et al. HIFa targeted for VHL-mediated destruction by proline hydroxylation: implications for $\mathrm{O}_{2}$ sensing. Science 2001: 292: 464-468.

33 Bruick R K, McKnight S L. A conserved family of prolyl-4-hydroxylases that modify HIF. Science 2001: 294: $1337-1340$.

34 Epstein A C, Gleadle J M, McNeill L A et al. C. elegans EGL-9 and mammalian homologs define a family of dioxygenases that regulate HIF by prolyl hydroxylation. 2001: 107: 43-54.

35 Ivan M, Haberberger T, Gervasi D C et al. Biochemical purification and pharmacological inhibition of a mammalian prolyl hydroxylase acting on hypoxia-inducible factor. Proc Natl Acad Sci U S A 2002: 99 : 13459-13464.

36 Ehrismann D, Flashman E, Genn D N et al. Studies on the activity of the hypoxia-inducible-factor hydroxylases using an oxygen consumption assay. Biochem J 2007: 401: 227-234.

This article is protected by copyright. All rights reserved 
37 Hirsilä M, Koivunen P, Günzler V et al. Characterization of the human prolyl 4-hydroxylases that modify the hypoxia-inducible factor. J Biol Chem 2003: 278: 30772-30780.

38 Koivunen $\mathrm{P}$, Hirsilä M, Kivirikko K I et al. The length of peptide substrates has a marked effect on hydroxylation by the hypoxia-inducible factor prolyl 4-hydroxylases. J Biol Chem 2006: 281: 28712-28720.

39 Loenarz C. An oxygen sensation: progress in macromolecule hydroxylation triggered by the elucidation of cellular oxygen sensing. Angew Chem Int Ed Engl 2020: 59: 3776-3780.

40 Chan M C, Holt-Martyn J P, Schofield C J et al. Pharmacological targeting of the HIF hydroxylases--A new field in medicine development. Mol Aspects Med 2016: 47-48: 54-75.

41 Rose N R, McDonough M A, King O N et al. Inhibition of 2-oxoglutarate dependent oxygenases. Chem Soc Rev 2011: 40: 4364-4397.

42 Hirsilä M, Koivunen P, Xu L et al. Effect of desferrioxamine and metals on the hydroxylases in the oxygen sensing pathway. FASEB J 2005: 19: 1308-1310.

43 Koivunen P, Hirsilä M, Remes A M et al. Inhibition of hypoxia-inducible factor (HIF) hydroxylases by citric acid cycle intermediates: possible links between cell metabolism and stabilization of HIF. J Biol Chem 2007: 282: 4524-4532.

44 Sanghani N S, Haase V H. Hypoxia-inducible factor activators in renal anemia: current clinical experience. Adv Chronic Kidney Dis 2019: 26: 253-266.

45 Schödel J, Ratcliffe P J. Mechanisms of hypoxia signalling: new implications for nephrology. Nat Rev Nephrol 2019: 15: 641-659.

46 Yeh T L, Leissing T M, Abboud M I et al. Molecular and cellular mechanisms of HIF prolyl hydroxylase inhibitors in clinical trials. Chem Sci 2017: 8: 7651-7668.

47 Berg R A, Prockop D J. The thermal transition of a non-hydroxylated form of collagen. Evidence for a role for hydroxyproline in stabilizing the triple-helix of collagen. Biochem Biophys Res Commun 1973: 52: $115-120$.

This article is protected by copyright. All rights reserved 
48 Butler W T, Piez K A, Bornstein P. Isolation and characterization of the cyanogen bromide peptides from the $\alpha-1$ chain of rat skin collagen. Biochemistry 1967: 6: 3771-3780.

49 Click E M, Bornstein P. Isolation and characterization of the cyanogen bromide peptides from the $\alpha 1$ and $\alpha 2$ chains of human skin collagen. Biochemistry 1970: 9: 4699-4706.

50 Fietzek P P, Kühn K. Information contained in the amino acid sequence of the $\alpha 1(\mathrm{I})$-chain of collagen and its consequences upon the formation of the triple helix, of fibrils and crosslinks. Mol Cell Biochem 1975: 8: 141-157.

51 An B, Abbonante $\mathrm{V}, \mathrm{Xu} \mathrm{H}$ et al. Recombinant collagen engineered to bind to discoidin domain receptor functions as a receptor inhibitor. J Biol Chem 2016: 291: 4343-4355.

52 Orgel, J P R O, Madhurapantula R S. A structural prospective for collagen receptors such as DDR and their binding of the collagen fibril. Biochim Biophys Acta Mol Cell Res 2019: 1866: 118478.

53 Sipilä K H, Drushinin K, Rappu P et al. Proline hydroxylation in collagen supports integrin binding by two distinct mechanisms. J Biol Chem 2018: 293: 7645-7658.

54 Myllyharju J. Prolyl 4-hydroxylases, the key enzymes of collagen biosynthesis. Matrix Biol 2003: 22: 1524.

55 Pihlajaniemi T, Helaakoski T, Tasanen K et al. Molecular cloning of the $\beta$-subunit of human prolyl 4hydroxylase. This subunit and protein disulphide isomerase are products of the same gene. EMBO J 1987: 6: 643-649.

56 Van Den Diepstraten C, Papay K, Bolender Z et al. Cloning of a novel prolyl 4-hydroxylase subunit expressed in the fibrous cap of human atherosclerotic plaque. Circulation 2003: 108: 508-511.

57 Kukkola L, Hieta R, Kivirikko K I et al. Identification and characterization of a third human, rat, and mouse collagen prolyl 4-hydroxylase isoenzyme. J Biol Chem 2003: 278: 47685-47693.

58 Bassuk J A, Kao W W, Herzer P et al. Prolyl 4-hydroxylase: molecular cloning and the primary structure of the $\alpha$ subunit from chicken embryo. Proc Natl Acad Sci U S A 1989: 86: 7382-7386.

This article is protected by copyright. All rights reserved 
59 Annunen P, Helaakoski T, Myllyharju J et al. Cloning of the human prolyl 4-hydroxylase $\alpha$ subunit isoform $\alpha(I I)$ and characterization of the type II enzyme tetramer. The $\alpha(I)$ and $\alpha(I I)$ subunits do not form a mixed $\alpha(I) \alpha(I I) \beta_{2}$ tetramer. J Biol Chem 1997: 272: 17342-17348.

60 Helaakoski T, Vuori K, Myllylä R et al. Molecular cloning of the $\alpha$-subunit of human prolyl 4hydroxylase: the complete cDNA-derived amino acid sequence and evidence for alternative splicing of RNA transcripts. Proc Natl Acad Sci U S A 1989: 86: 4392-4396.

61 Helaakoski T, Annunen P, Vuori K et al. Cloning, baculovirus expression, and characterization of a second mouse prolyl 4-hydroxylase $\alpha$-subunit isoform: formation of an $\alpha_{2} \beta_{2}$ tetramer with the protein disulfide-isomerase/ $\beta$ subunit. Proc Natl Acad Sci U S A 1995: 92: 4427-4431.

62 Vuori K, Pihlajaniemi T, Marttila M et al. Characterization of the human prolyl 4-hydroxylase tetramer and its multifunctional protein disulfide-isomerase subunit synthesized in a baculovirus expression system. Proc Natl Acad Sci U S A 1992: 89: 7467-7470.

63 Vuori K, Pihlajaniemi T, Myllylä R et al. Site-directed mutagenesis of human protein disulphide isomerase: effect on the assembly, activity and endoplasmic reticulum retention of human prolyl 4hydroxylase in Spodoptera frugiperda insect cells. EMBO J 1992: 11: 4213-4217.

64 John D C, Grant M E, Bulleid N J. Cell-free synthesis and assembly of prolyl 4-hydroxylase: the role of the $\beta$-subunit (PDI) in preventing misfolding and aggregation of the $\alpha$-subunit. EMBO J 1993: 12: 15871595.

65 John D C, Bulleid N J. Prolyl 4-hydroxylase: defective assembly of $\alpha$-subunit mutants indicates that assembled $\alpha$-subunits are intramolecularly disulfide bonded. Biochemistry 1994: 33: 14018-14025.

66 Lamberg A, Pihlajaniemi T, Kivirikko K I. Site-directed mutagenesis of the a subunit of human prolyl 4hydroxylase. Identification of three histidine residues critical for catalytic activity. J Biol Chem 1995: 270: 9926-9931.

67 Koivunen P, Helaakoski T, Annunen P et al. ERp60 does not substitute for protein disulphide isomerase as the $\beta$-subunit of prolyl 4-hydroxylase. Biochem J 1996: 316 ( Pt 2): 599-605.

This article is protected by copyright. All rights reserved 
68 Koski M K, Anantharajan J, Kursula P et al. Assembly of the elongated collagen prolyl 4-hydroxylase $\alpha_{2} \beta_{2}$ heterotetramer around a central $\alpha_{2}$ dimer. Biochem J 2017: 474: 751-769.

69 Myllyharju J, Kivirikko K I. Identification of a novel proline-rich peptide-binding domain in prolyl 4hydroxylase. EMBO J 1999: 18: 306-312.

70 Anantharajan J, Koski M K, Kursula P et al. The structural motifs for substrate binding and dimerization of the $\alpha$ subunit of collagen prolyl 4-hydroxylase. Structure 2013: 21: 2107-2118.

71 Murthy A V, Sulu R, Koski M K et al. Structural enzymology binding studies of the peptide-substratebinding domain of human collagen prolyl 4-hydroxylase (type-II): High affinity peptides have a PxGP sequence motif. Protein Sci 2018: 27: 1692-1703.

72 Wang C, Li W, Ren J et al. Structural insights into the redox-regulated dynamic conformations of human protein disulfide isomerase. Antioxid Redox Signal 2013: 19: 36-45.

73 Myllyharju J, Kivirikko K I. Characterization of the iron- and 2-oxoglutarate-binding sites of human prolyl 4-hydroxylase. EMBO J 1997: 16: 1173-1180.

74 Islam M S, Leissing T M, Chowdhury R et al. 2-Oxoglutarate-dependent oxygenases. Annu Rev Biochem 2018: 87: 585-620.

75 Koski M K, Hieta R, Hirsilä M et al. The crystal structure of an algal prolyl 4-hydroxylase complexed with a proline-rich peptide reveals a novel buried tripeptide binding motif. J Biol Chem 2009: 284: 2529025301.

76 McDonough M A, Li V, Flashman E et al. Cellular oxygen sensing: Crystal structure of hypoxia-inducible factor prolyl hydroxylase (PHD2). Proc Natl Acad Sci U S A 2006: 103: 9814-9819.

77 Koski M K, Hieta R, Böllner C et al. The active site of an algal prolyl 4-hydroxylase has a large structural plasticity. J Biol Chem 2007: 282: 37112-37123.

78 Chowdhury R, McDonough M A, Mecinovic J et al. Structural basis for binding of hypoxia-inducible factor to the oxygen-sensing prolyl hydroxylases. Structure 2009: 17: 981-989.

This article is protected by copyright. All rights reserved 
79 Aro E, Khatri R, Gerard-O'Riley R et al. Hypoxia-inducible factor-1 (HIF-1) but not HIF-2 is essential for hypoxic induction of collagen prolyl 4-hydroxylases in primary newborn mouse epiphyseal growth plate chondrocytes. J Biol Chem 2012: 287: 37134-37144.

80 Myllyharju J, Schipani E. Extracellular matrix genes as hypoxia-inducible targets. Cell Tissue Res 2010: 339: $19-29$.

81 Bentovim L, Amarilio R, Zelzer E. HIF1 $\alpha$ is a central regulator of collagen hydroxylation and secretion under hypoxia during bone development. Development 2012: 139: 4473-4483.

82 Gilkes D M, Bajpai S, Chaturvedi P et al. Hypoxia-inducible factor 1 (HIF-1) promotes extracellular matrix remodeling under hypoxic conditions by inducing P4HA1, P4HA2, and PLOD2 expression in fibroblasts. J Biol Chem 2013: 288: 10819-10829.

83 Gilkes D M, Semenza G L, Wirtz D. Hypoxia and the extracellular matrix: drivers of tumour metastasis. Nat Rev Cancer 2014: 14: 430-439.

84 Gilkes D M, Chaturvedi P, Bajpai S et al. Collagen prolyl hydroxylases are essential for breast cancer metastasis. Cancer Res 2013: 73: 3285-3296.

85 Gilkes D M, Bajpai S, Wong C C et al. Procollagen lysyl hydroxylase 2 is essential for hypoxia-induced breast cancer metastasis. Mol Cancer Res 2013: 11: 456-466.

86 Laitala A, Erler J T. Hypoxic signalling in tumour stroma. Front Oncol 2018: 8: 189.

87 Zou Y, Donkervoort S, Salo A M et al. P4HA1 mutations cause a unique congenital disorder of connective tissue involving tendon, bone, muscle and the eye. Hum Mol Genet 2017: 26: 2207-2217.

88 Guo H, Tong P, Liu Y et al. Mutations of P4HA2 encoding prolyl 4-hydroxylase 2 are associated with nonsyndromic high myopia. Genet Med 2015: 17: 300-306.

89 Napolitano F, Di lorio V, Testa F et al. Autosomal-dominant myopia associated to a novel P4HA2 missense variant and defective collagen hydroxylation. Clin Genet 2018: 93: 982-991.

This article is protected by copyright. All rights reserved 
90 Annunen P, Autio-Harmainen H, Kivirikko K I. The novel type II prolyl 4-hydroxylase is the main enzyme form in chondrocytes and capillary endothelial cells, whereas the type I enzyme predominates in most cells. J Biol Chem 1998: 273: 5989-5992.

91 Nissi R, Autio-Harmainen H, Marttila P et al. Prolyl 4-hydroxylase isoenzymes I and II have different expression patterns in several human tissues. J Histochem Cytochem 2001: 49: 1143-1153.

92 Holster T, Pakkanen O, Soininen R et al. Loss of assembly of the main basement membrane collagen, type IV, but not fibril-forming collagens and embryonic death in collagen prolyl 4-hydroxylase I null mice. J Biol Chem 2007: 282: 2512-2519.

93 Aro E, Salo A M, Khatri R et al. Severe extracellular matrix abnormalities and chondrodysplasia in mice lacking collagen prolyl 4-hydroxylase isoenzyme II in combination with a reduced amount of isoenzyme I. J Biol Chem 2015: 290: 16964-16978.

94 Maes C, Carmeliet G, Schipani E. Hypoxia-driven pathways in bone development, regeneration and disease. Nat Rev Rheumatol 2012: 8: 358-366.

95 Schipani E, Mangiavini L, Merceron C. HIF-1 $\alpha$ and growth plate development: what we really know. Bonekey Rep 2015: 4: 730.

96 Stegen S, Laperre K, Eelen G et al. HIF-1 $\alpha$ metabolically controls collagen synthesis and modification in chondrocytes. Nature 2019: 565: 511-515.

97 Marini J C, Reich A, Smith S M. Osteogenesis imperfecta due to mutations in non-collagenous genes: lessons in the biology of bone formation. Curr Opin Pediatr 2014: 26: 500-507.

98 Hudson D M, Eyre D R. Collagen prolyl 3-hydroxylation: a major role for a minor post-translational modification? Connect Tissue Res 2013: 54: 245-251.

99 Hudson D M, Kim L S, Weis M et al. Peptidyl 3-hydroxyproline binding properties of type I collagen suggest a function in fibril supramolecular assembly. Biochemistry 2012: 51: 2417-2424.

100 Weis M A, Hudson D M, Kim L et al. Location of 3-hydroxyproline residues in collagen types I, II, III, and V/XI implies a role in fibril supramolecular assembly. J Biol Chem 2010: 285: 2580-2590.

This article is protected by copyright. All rights reserved 
101 Montgomery N T, Zientek K D, Pokidysheva E N et al. Post-translational modification of type IV collagen with 3-hydroxyproline affects its interactions with glycoprotein VI and nidogens 1 and 2. J Biol Chem 2018: 293: 5987-5999.

102 Ogle J D, Arlinghaus R B, Lgan M A. 3-Hydroxyproline, a new amino acid of collagen. J Biol Chem 1962: 237: 3667-3673.

103 Gryder R M, Lamon M, Adams E. Sequence position of 3-hydroxyproline in basement membrane collagen. Isolation of glycyl-3-hydroxyprolyl-4-hydroxyproline from swine kidney. J Biol Chem 1975: 250: 2470-2474.

104 Yang C, Park A C, Davis N A et al. Comprehensive mass spectrometric mapping of the hydroxylated amino acid residues of the $\alpha 1(\mathrm{~V})$ collagen chain. J Biol Chem 2012: 287: 40598-40610.

105 Basak T, Vega-Montoto L, Zimmerman L J et al. Comprehensive characterization of glycosylation and hydroxylation of basement membrane collagen IV by high-resolution mass spectrometry. J Proteome Res 2016: 15: 245-258.

106 Dean D C, Barr J F, Freytag J W et al. Isolation of type IV procollagen-like polypeptides from glomerular basement membrane. Characterization of pro- $\alpha 1$ (IV). J Biol Chem 1983: 258: 590-596.

107 Eyre D R, Weis M, Hudson D M et al. A novel 3-hydroxyproline (3Hyp)-rich motif marks the triplehelical C terminus of tendon type I collagen. J Biol Chem 2011: 286: 7732-7736.

108 Hudson D M, Werther R, Weis M et al. Evolutionary origins of C-terminal (GPP) ${ }_{n}$ 3-hydroxyproline formation in vertebrate tendon collagen. PLoS One 2014: 9: e93467.

109 Vranka J A, Sakai L Y, Bächinger H P. Prolyl 3-hydroxylase 1, enzyme characterization and identification of a novel family of enzymes. J Biol Chem 2004: 279: 23615-23621.

110 Marini J C, Cabral W A, Barnes A M et al. Components of the collagen prolyl 3-hydroxylation complex are crucial for normal bone development. Cell Cycle 2007: 6: 1675-1681.

111 Ishikawa Y, Wirz J, Vranka J A et al. Biochemical characterization of the prolyl 3-hydroxylase 1.cartilage-associated protein.cyclophilin B complex. J Biol Chem 2009: 284: 17641-17647.

This article is protected by copyright. All rights reserved 
112 Chang W, Barnes A M, Cabral W A et al. Prolyl 3-hydroxylase 1 and CRTAP are mutually stabilizing in the endoplasmic reticulum collagen prolyl 3-hydroxylation complex. Hum Mol Genet 2010: 19: 223-234.

113 Tiainen P, Pasanen A, Sormunen R et al. Characterization of recombinant human prolyl 3-hydroxylase isoenzyme 2, an enzyme modifying the basement membrane collagen IV. J Biol Chem 2008: 283: 1943219439.

114 Hudson D M, Joeng K S, Werther R et al. Post-translationally abnormal collagens of prolyl 3hydroxylase-2 null mice offer a pathobiological mechanism for the high myopia linked to human LEPREL1 mutations. J Biol Chem 2015: 290: 8613-8622.

115 Vranka J, Stadler H S, Bächinger H P. Expression of prolyl 3-hydroxylase genes in embryonic and adult mouse tissues. Cell Struct Funct 2009: 34: 97-104.

116 Hudson D M, Weis M, Rai J et al. P3h3-null and Sc65-null mice phenocopy the collagen lysine underhydroxylation and cross-linking abnormality of Ehlers-Danlos syndrome type VIA. J Biol Chem 2017: 292: 3877-3887.

117 Heard M E, Besio R, Weis M et al. Sc65-null mice provide evidence for a novel endoplasmic reticulum complex regulating collagen lysyl hydroxylation. PLoS Genet 2016: 12: e1006002.

118 Terajima M, Taga Y, Cabral W A et al. Cyclophilin B control of lysine post-translational modifications of skin type I collagen. PLoS Genet 2019: 15: e1008196.

119 Terajima M, Taga Y, Chen Y et al. Cyclophilin-B modulates collagen cross-linking by differentially affecting lysine hydroxylation in the helical and telopeptidyl domains of tendon type I collagen. J Biol Chem 2016: 291: 9501-9512.

120 Forlino A, Marini J C. Osteogenesis imperfecta. Lancet 2016: 387: 1657-1671.

121 Marini J C, Forlino A, Bächinger H P et al. Osteogenesis imperfecta. Nat Rev Dis Primers 2017: 3: 17052.

122 Marini J C, Blissett A R. New genes in bone development: what's new in osteogenesis imperfecta. J Clin Endocrinol Metab 2013: 98: 3095-3103.

This article is protected by copyright. All rights reserved 
123 Forlino A, Cabral W A, Barnes A M et al. New perspectives on osteogenesis imperfecta. Nat Rev Endocrinol 2011: 7: 540-557.

124 Feng $C Y$, Huang $X Q$, Cheng $X W$ et al. Mutational screening of SLC39A5, LEPREL1 and LRPAP1 in a cohort of 187 high myopia patients. Sci Rep 2017: 7: 1120-3.

125 Guo H, Tong P, Peng Y et al. Homozygous loss-of-function mutation of the LEPREL1 gene causes severe non-syndromic high myopia with early-onset cataract. Clin Genet 2014: 86: 575-579.

126 Jiang D, Li J, Xiao X et al. Detection of mutations in LRPAP1, CTSH, LEPREL1, ZNF644, SLC39A5, and SCO2 in 298 families with early-onset high myopia by exome sequencing. Invest Ophthalmol Vis Sci 2014: 56: 339-345.

127 Khan A O, Aldahmesh M A, Alsharif $\mathrm{H}$ et al. Recessive mutations in LEPREL1 underlie a recognizable lens subluxation phenotype. Ophthalmic Genet 2015: 36: 58-63.

128 Mordechai S, Gradstein L, Pasanen A et al. High myopia caused by a mutation in LEPREL1, encoding prolyl 3-hydroxylase 2. Am J Hum Genet 2011: 89: 438-445.

129 Vranka J A, Pokidysheva E, Hayashi L et al. Prolyl 3-hydroxylase 1 null mice display abnormalities in fibrillar collagen-rich tissues such as tendons, skin, and bones. J Biol Chem 2010: 285: 17253-17262.

130 Fratzl-Zelman N, Bächinger H P, Vranka J A et al. Bone matrix hypermineralization in prolyl-3 hydroxylase 1 deficient mice. Bone 2016: 85: 15-22.

131 Morello R, Bertin T K, Chen Y et al. CRTAP is required for prolyl 3- hydroxylation and mutations cause recessive osteogenesis imperfecta. Cell 2006: 127: 291-304.

132 Baldridge D, Lennington J, Weis $\mathrm{M}$ et al. Generalized connective tissue disease in Crtap ${ }^{-/}$mouse. PLoS One 2010: 5: e10560.

133 Cabral W A, Perdivara I, Weis M et al. Abnormal type I collagen post-translational modification and crosslinking in a cyclophilin B KO mouse model of recessive osteogenesis imperfecta. PLoS Genet 2014: 10: e1004465.

This article is protected by copyright. All rights reserved 
134 Choi J W, Sutor S L, Lindquist L et al. Severe osteogenesis imperfecta in cyclophilin B-deficient mice. PLoS Genet 2009: 5: e1000750.

135 Cabral W A, Fratzl-Zelman N, Weis M et al. Substitution of murine type I collagen A1 3-hydroxylation site alters matrix structure but does not recapitulate osteogenesis imperfecta bone dysplasia. Matrix Biol 2020: 90: 20-39.

136 Pokidysheva E, Boudko S, Vranka J et al. Biological role of prolyl 3-hydroxylation in type IV collagen. Proc Natl Acad Sci U S A 2014: 111: 161-166.

137 Gruenwald K, Castagnola P, Besio R et al. Sc65 is a novel endoplasmic reticulum protein that regulates bone mass homeostasis. J Bone Miner Res 2014: 29: 666-675.

138 Takaluoma K, Hyry M, Lantto J et al. Tissue-specific changes in the hydroxylysine content and crosslinks of collagens and alterations in fibril morphology in lysyl hydroxylase 1 knock-out mice. J Biol Chem 2007: 282: 6588-6596.

139 Kivirikko K I, Pihlajaniemi T. Collagen hydroxylases and the protein disulfide isomerase subunit of prolyl 4-hydroxylases. Adv Enzymol Relat Areas Mol Biol 1998: 72: 325-398.

140 Eyre D R, Weis M A. Bone collagen: new clues to its mineralization mechanism from recessive osteogenesis imperfecta. Calcif Tissue Int 2013: 93: 338-347.

141 Yamauchi M, Terajima M, Shiiba M. Lysine hydroxylation and cross-linking of collagen. Methods Mol Biol 2019: 1934: 309-324.

142 Yamauchi M, Sricholpech M. Lysine post-translational modifications of collagen. Essays Biochem 2012: 52: 113-133.

143 Hautala T, Byers M G, Eddy R L et al. Cloning of human lysyl hydroxylase: complete CDNA-derived amino acid sequence and assignment of the gene (PLOD) to chromosome 1p36.3----p36.2. Genomics 1992: 13: 62-69.

144 Passoja K, Rautavuoma K, Ala-Kokko L et al. Cloning and characterization of a third human lysyl hydroxylase isoform. Proc Natl Acad Sci U S A 1998: 95: 10482-10486.

This article is protected by copyright. All rights reserved 
145 Valtavaara M, Papponen H, Pirttilä A M et al. Cloning and characterization of a novel human lysyl hydroxylase isoform highly expressed in pancreas and muscle. J Biol Chem 1997: 272: 6831-6834.

146 Valtavaara M, Szpirer C, Szpirer J et al. Primary structure, tissue distribution, and chromosomal localization of a novel isoform of lysyl hydroxylase (lysyl hydroxylase 3). J Biol Chem 1998: 273: 1288112886.

147 Mercer D K, Nicol P F, Kimbembe C et al. Identification, expression, and tissue distribution of the three rat lysyl hydroxylase isoforms. Biochem Biophys Res Commun 2003: 307: 803-809.

148 Scietti L, Chiapparino A, De Giorgi F et al. Molecular architecture of the multifunctional collagen lysyl hydroxylase and glycosyltransferase LH3. Nat Commun 2018: 9: 3163-5.

149 Myllylä R, Pajunen L, Kivirikko K I. Polyclonal and monoclonal antibodies to human lysyl hydroxylase and studies on the molecular heterogeneity of the enzyme. Biochem J 1988: 253: 489-496.

150 Heikkinen J, Risteli M, Lampela O et al. Dimerization of human lysyl hydroxylase 3 (LH3) is mediated by the amino acids 541-547. Matrix Biol 2011: 30: 27-33.

151 Gjaltema R A, van der Stoel, M M, Boersema M et al. Disentangling mechanisms involved in collagen pyridinoline cross-linking: The immunophilin FKBP65 is critical for dimerization of lysyl hydroxylase 2. Proc Natl Acad Sci U S A 2016: 113: 7142-7147.

152 Turpeenniemi-Hujanen T M, Puistola U, Kivirikko K I. Isolation of lysyl hydroxylase, an enzyme of collagen synthesis, from chick embryos as a homogeneous protein. Biochem J 1980: 189: 247-253.

153 Takaluoma K, Lantto J, Myllyharju J. Lysyl hydroxylase 2 is a specific telopeptide hydroxylase, while all three isoenzymes hydroxylate collagenous sequences. Matrix Biol 2007: 26: 396-403.

154 Uzawa K, Grzesik W J, Nishiura T et al. Differential expression of human lysyl hydroxylase genes, lysine hydroxylation, and cross-linking of type I collagen during osteoblastic differentiation in vitro. J Bone Miner Res 1999: 14: 1272-1280.

155 van der Slot, A J, Zuurmond A M, Bardoel A F et al. Identification of PLOD2 as telopeptide lysyl hydroxylase, an important enzyme in fibrosis. J Biol Chem 2003: 278: 40967-40972.

This article is protected by copyright. All rights reserved 
156 Yeowell H N, Walker L C. Tissue specificity of a new splice form of the human lysyl hydroxylase 2 gene. Matrix Biol 1999: 18: 179-187.

157 van der Slot, A J, van Dura E A, de Wit E C et al. Elevated formation of pyridinoline cross-links by profibrotic cytokines is associated with enhanced lysyl hydroxylase $2 \mathrm{~b}$ levels. Biochim Biophys Acta 2005: 1741: 95-102.

158 Pornprasertsuk S, Duarte W R, Mochida Y et al. Lysyl hydroxylase-2b directs collagen cross-linking pathways in MC3T3-E1 cells. J Bone Miner Res 2004: 19: 1349-1355.

159 Heikkinen J, Risteli M, Wang C et al. Lysyl hydroxylase 3 is a multifunctional protein possessing collagen glucosyltransferase activity. J Biol Chem 2000: 275: 36158-36163.

160 Wang C, Luosujarvi H, Heikkinen J et al. The third activity for lysyl hydroxylase 3: galactosylation of hydroxylysyl residues in collagens in vitro. Matrix Biol 2002: 21: 559-566.

161 Rautavuoma K, Takaluoma K, Passoja K et al. Characterization of three fragments that constitute the monomers of the human lysyl hydroxylase isoenzymes 1-3. The 30-kDa N-terminal fragment is not required for lysyl hydroxylase activity. J Biol Chem 2002: 277: 23084-23091.

162 Schegg B, Hulsmeier A J, Rutschmann C et al. Core glycosylation of collagen is initiated by two $\beta(1-$ O)galactosyltransferases. Mol Cell Biol 2009: 29: 943-952.

163 Terajima M, Taga Y, Sricholpech M et al. Role of glycosyltransferase 25 domain 1 in type I collagen glycosylation and molecular phenotypes. Biochemistry 2019: 58: 5040-5051.

164 Ruotsalainen H, Sipilä L, Vapola M et al. Glycosylation catalyzed by lysyl hydroxylase 3 is essential for basement membranes. J Cell Sci 2006: 119: 625-635.

165 Sricholpech M, Perdivara I, Yokoyama M et al. Lysyl hydroxylase 3-mediated glucosylation in type I collagen: molecular loci and biological significance. J Biol Chem 2012: 287: 22998-23009.

166 Rautavuoma K, Takaluoma K, Sormunen R et al. Premature aggregation of type IV collagen and early lethality in lysyl hydroxylase 3 null mice. Proc Natl Acad Sci U S A 2004: 101: 14120-14125.

This article is protected by copyright. All rights reserved 
167 Sipilä L, Ruotsalainen H, Sormunen R et al. Secretion and assembly of type IV and VI collagens depend on glycosylation of hydroxylysines. J Biol Chem 2007: 282: 33381-33388.

168 Salo A M, Wang C, Sipilä L et al. Lysyl hydroxylase 3 (LH3) modifies proteins in the extracellular space, a novel mechanism for matrix remodeling. J Cell Physiol 2006: 207: 644-653.

169 Banushi B, Forneris F, Straatman-Iwanowska A et al. Regulation of post-Golgi LH3 trafficking is essential for collagen homeostasis. Nat Commun 2016: 7: 12111.

170 Suokas M, Lampela O, Juffer A H et al. Retrieval-independent localization of lysyl hydroxylase in the endoplasmic reticulum via a peptide fold in its iron-binding domain. Biochem J 2003: 370: 913-920.

171 Scietti L, Campioni M, Forneris F. SiMPLOD, a structure-integrated database of collagen lysyl hydroxylase (LH/PLOD) enzyme variants. J Bone Miner Res 2019: 34: 1376-1382.

172 Duran I, Martin J H, Weis M A et al. A chaperone complex formed by HSP47, FKBP65, and BiP modulates telopeptide lysyl hydroxylation of type I procollagen. J Bone Miner Res 2017: 32: 1309-1319.

173 Ishikawa Y, Holden P, Bächinger H P. Heat shock protein 47 and 65-kDa FK506-binding protein weakly but synergistically interact during collagen folding in the endoplasmic reticulum. J Biol Chem 2017: 292: 17216-17224.

174 Kelley B P, Malfait F, Bonafe L et al. Mutations in FKBP10 cause recessive osteogenesis imperfecta and Bruck syndrome. J Bone Miner Res 2011: 26: 666-672.

175 Giunta C, Baumann M, Fauth C et al. A cohort of 17 patients with kyphoscoliotic Ehlers-Danlos syndrome caused by biallelic mutations in FKBP14: expansion of the clinical and mutational spectrum and description of the natural history. Genet Med 2018: 20: 42-54.

176 Yeowell H N, Steinmann B. PLOD1-related kyphoscoliotic Ehlers-Danlos syndrome. In: Adam M P, Ardinger H H, Pagon R A et al., eds. GeneReviews((R)). Seattle (WA): University of Washington, Seattle. GeneReviews is a registered trademark of the University of Washington, Seattle. All rights reserved, 1993.

177 Eyre D, Shao P, Weis M A et al. The kyphoscoliotic type of Ehlers-Danlos syndrome (type VI): differential effects on the hydroxylation of lysine in collagens I and II revealed by analysis of cross-linked telopeptides from urine. Mol Genet Metab 2002: 76: 211-216.

This article is protected by copyright. All rights reserved 
178 Steinmann B, Eyre D R, Shao P. Urinary pyridinoline cross-links in Ehlers-Danlos syndrome type VI. Am J Hum Genet 1995: 57: 1505-1508.

179 Giunta C, Randolph A, Al-Gazali L I et al. Nevo syndrome is allelic to the kyphoscoliotic type of the Ehlers-Danlos syndrome (EDS VIA). Am J Med Genet A 2005: 133A: 158-164.

180 Baumann M, Giunta C, Krabichler B et al. Mutations in FKBP14 cause a variant of Ehlers-Danlos syndrome with progressive kyphoscoliosis, myopathy, and hearing loss. Am J Hum Genet 2012: 90: 201216.

181 Bank R A, Robins S P, Wijmenga C et al. Defective collagen crosslinking in bone, but not in ligament or cartilage, in Bruck syndrome: indications for a bone-specific telopeptide lysyl hydroxylase on chromosome 17. Proc Natl Acad Sci U S A 1999: 96: 1054-1058.

182 Ha-Vinh R, Alanay Y, Bank R A et al. Phenotypic and molecular characterization of Bruck syndrome (osteogenesis imperfecta with contractures of the large joints) caused by a recessive mutation in PLOD2. Am J Med Genet A 2004: 131: 115-120.

183 Hyry M, Lantto J, Myllyharju J. Missense mutations that cause Bruck syndrome affect enzymatic activity, folding, and oligomerization of lysyl hydroxylase 2. J Biol Chem 2009: 284: 30917-30924.

184 Barnes A M, Duncan G, Weis M et al. Kuskokwim syndrome, a recessive congenital contracture disorder, extends the phenotype of FKBP10 mutations. Hum Mutat 2013: 34: 1279-1288.

185 Salo A M, Cox H, Farndon P et al. A connective tissue disorder caused by mutations of the lysyl hydroxylase 3 gene. Am J Hum Genet 2008: 83: 495-503.

186 Maddirevula S, Alzahrani F, Al-Owain M et al. Autozygome and high throughput confirmation of disease genes candidacy. Genet Med 2019: 21: 736-742.

187 Vahidnezhad H, Youssefian L, Saeidian A H et al. Mutations in PLOD3, encoding lysyl hydroxylase 3, cause a complex connective tissue disorder including recessive dystrophic epidermolysis bullosa-like blistering phenotype with abnormal anchoring fibrils and type VII collagen deficiency. Matrix Biol 2019: 81: 91-106.

This article is protected by copyright. All rights reserved 
188 Ewans L J, Colley A, Gaston-Massuet C et al. Pathogenic variants in PLOD3 result in a Stickler syndrome-like connective tissue disorder with vascular complications. J Med Genet 2019: 56: 629-638.

189 Hyry M. Lysyl hydroxylases 1 and 2: characterization of their in vivo roles in mouse and the molecular level consequences of the lysyl hydroxylase 2 mutations found in Bruck syndrome. Acta Universitatis Ouluensis D Medica, 2012. http://jultika.oulu.fi/Record/isbn978-951-42-9842-4

190 Kasamatsu A, Uzawa K, Hayashi F et al. Deficiency of lysyl hydroxylase 2 in mice causes systemic endoplasmic reticulum stress leading to early embryonic lethality. Biochem Biophys Res Commun 2019: 512: 486-491.

191 Lietman C D, Rajagopal A, Homan E P et al. Connective tissue alterations in Fkbp10/- mice. Hum Mol Genet 2014: 23: 4822-4831.

192 Lietman C D, Lim J, Grafe I et al. Fkbp10 deletion in osteoblasts leads to qualitative defects in bone. J Bone Miner Res 2017: 32: 1354-1367.

193 Geister K A, Lopez-Jimenez A J, Houghtaling S et al. Loss of function of Colgalt1 disrupts collagen posttranslational modification and causes musculoskeletal defects. Dis Model Mech 2019: 12: 10.1242/dmm.037176.

194 Hao X, Liu R, Zhang Y et al. Glt25d2 knockout directly increases CD25+CD69- but decreases CD25$\mathrm{CD}^{2} 9^{+}$subset proliferation and is involved in concanavalin-induced hepatitis. Cell Physiol Biochem 2018: 50: $1186-1200$.

195 Rauch F, Fahiminiya S, Majewski J et al. Cole-Carpenter syndrome is caused by a heterozygous missense mutation in P4HB. Am J Hum Genet 2015: 96: 425-431.

196 Ouyang L, Yang F. Cole-Carpenter syndrome-1 with a de novo heterozygous deletion in the P4HB gene in a Chinese girl: A case report. Medicine (Baltimore) 2017: 96: e9504.

197 Balasubramanian M, Padidela R, Pollitt R C et al. P4HB recurrent missense mutation causing ColeCarpenter syndrome. J Med Genet 2018: 55: 158-165.

This article is protected by copyright. All rights reserved 
198 Giunta C, Rohrbach M, Fauth C et al. FKBP14 Kyphoscoliotic Ehlers-Danlos syndrome. In: Adam M P, Ardinger H H, Pagon R A et al., eds. GeneReviews ${ }^{\circledR}$. Seattle (WA): University of Washington, Seattle.

GeneReviews is a registered trademark of the University of Washington, Seattle. All rights reserved, 1993.

199 Miyatake S, Schneeberger S, Koyama N et al. Biallelic COLGALT1 variants are associated with cerebral small vessel disease. Ann Neurol 2018: 84: 843-853.

This article is protected by copyright. All rights reserved 


\section{Figure legends}

Fig. 1. Schematic figure of the collagen hydroxylases and modifications catalyzed by them. Collagen $\mathrm{P} 4 \mathrm{H}$; the $\mathrm{N}$-terminal dimerization domain (N), peptide-substrate-binding domain (PSB) and the catalytic domain (CAT) of the $\alpha$ subunit as well as the $a, b, b^{\prime}$ and $a^{\prime}$ domains of the $\beta / P D I$ subunit are indicated. LH and LH3; The N-terminal (N) or glycosyltransferase (GT) domain in case of LH3, accessory domain (AC) and LH activity domain (LH) are indicated. $\mathrm{P} 3 \mathrm{H}$; the P3H1:CRTAP:CYPB complex constituents are indicated. The collagen P4H and LH3 structures are sketched according to SAXS (68) and X ray crystal (148) structures, respectively, while no structural data exists of the organization of the P3H1:CRTAP:CYPB complex and the drawing is thus purely hypothetical.

Fig. 2. Schematic figure of the role of collagen prolyl 4-hydroxylation. The thermal stability of the collagen triple helix is critically dependent on 4 Hyp residues and a decrease in (dashed red cross) or lack of (solid red cross) prolyl 4-hydroxylation causes a local or complete loss of the triple-helical structure at human body temperature.

Fig. 3. The collagen Lys and Hyl residues participate in collagen cross-linking and the chemical nature of the cross-links is determined by the lysyl hydroxylation status. Hydroxylation of the telopeptide (a short non-triple-helical region at both ends of the triple helical region, indicated as an orange line in the collagen molecule) lysines is a prerequisite for the formation of mature trivalent pyridinoline cross-links, and the presence of Hyl or Lys in the cross-linking site of the triple helix (indicated as a black line in the collagen molecule) determines whether hydroxylysylpyridinoline (HP) or lysylpyridinoline (LP) cross-links, respectively, are formed. Among the $\mathrm{LH}$ isoenzymes, $\mathrm{LH} 2$ is the only one capable of hydroxylating the telopeptide lysines, while LH1 is the main enzyme responsible for the hydroxylation of lysines in the triplehelical region. LH3, in addition to possessing LH activity, acts as a collagen galactosyl-Hyl glucosyltransferase and to a low extent also as a collagen galactosyltransferase. Lack of or reduced activity of the individual LH isoenzymes has isoenzyme-specific outcomes on the collagen cross-link chemistry. Furthermore, lack of LH3 activity leads to loss of glucosylated galactosyl-Hyl residues.

This article is protected by copyright. All rights reserved 
Table 1. Human mutations and transgenic mouse phenotypes in collagen proline and lysine modification pathways

\begin{tabular}{|c|c|c|c|c|c|}
\hline Human Gene & Protein & $\begin{array}{l}\text { Protein } \\
\text { function }\end{array}$ & $\begin{array}{l}\text { Human } \\
\text { disorder }\end{array}$ & $\begin{array}{l}\text { Description / } \\
\text { further } \\
\text { information }\end{array}$ & Mouse phenotype \\
\hline
\end{tabular}

Prolyl 4-hydroxylation related genes, proteins and phenotypes

P4HA1

$\begin{array}{lll}\text { Collagen } & \text { Prolyl 4- } & \text { Connective } \\ \text { P4H I, } \alpha_{2} \beta_{2} & \text { hydroxylase } & \text { tissues disorder } \\ \text { tetramer } & & \text { affecting } \\ \text { with PDI } & \text { tendon, bone, } \\ & \text { muscle and the } \\ & \text { eye }\end{array}$

P4HA2

$\begin{array}{ll}\text { Collagen } & \text { Prolyl 4- } \\ \text { P4H II, } \alpha_{2} \beta_{2} & \text { hydroxylase }\end{array}$

tetramer

with PDI

\section{Myopia}

Single family with
compound
heterozygous
mutation. Reduced
collagen $\mathrm{P} 4 \mathrm{H}$
activity

Heterozygous

mutations

Compound mutant

P4ha1 ${ }^{+/-} ;$P4ha2 ${ }^{-/}$
KOs exhibit early

embryonic lethality

after $10.5 \mathrm{dpc}$,

basement membrane

defects

KOs have minor

phenotypic changes

Smaller that littermates,

moderate

chondrodysplasia,

transient inner cell

death phenotype in

growth plates,

biomechanically

impaired ECM

$\alpha_{2} \beta_{2}$

tetramer

with PDI

P4HB

PDI

Protein
disulfide

Cole-Carpenter

heterozygous

mutations

(195-197)

isomerase

Prolyl 3-hydroxylation related genes, proteins and phenotypes

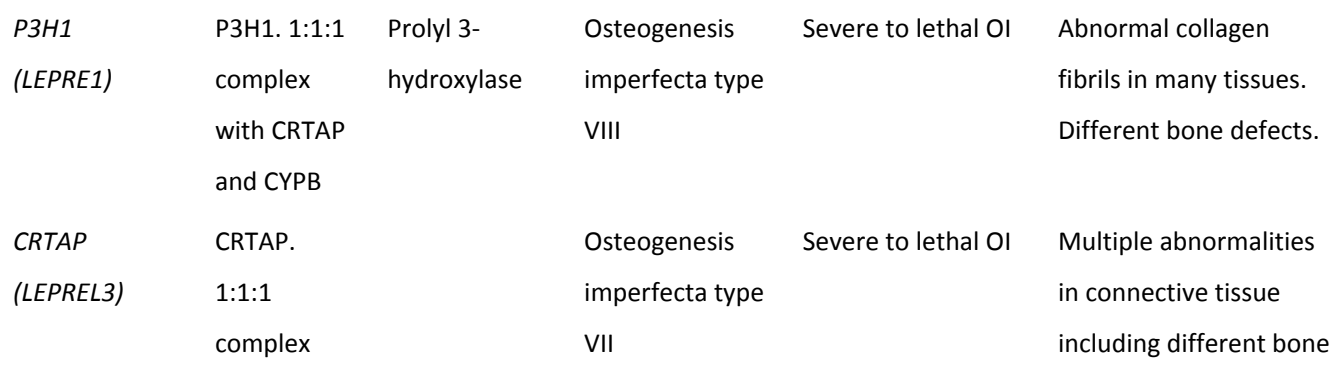




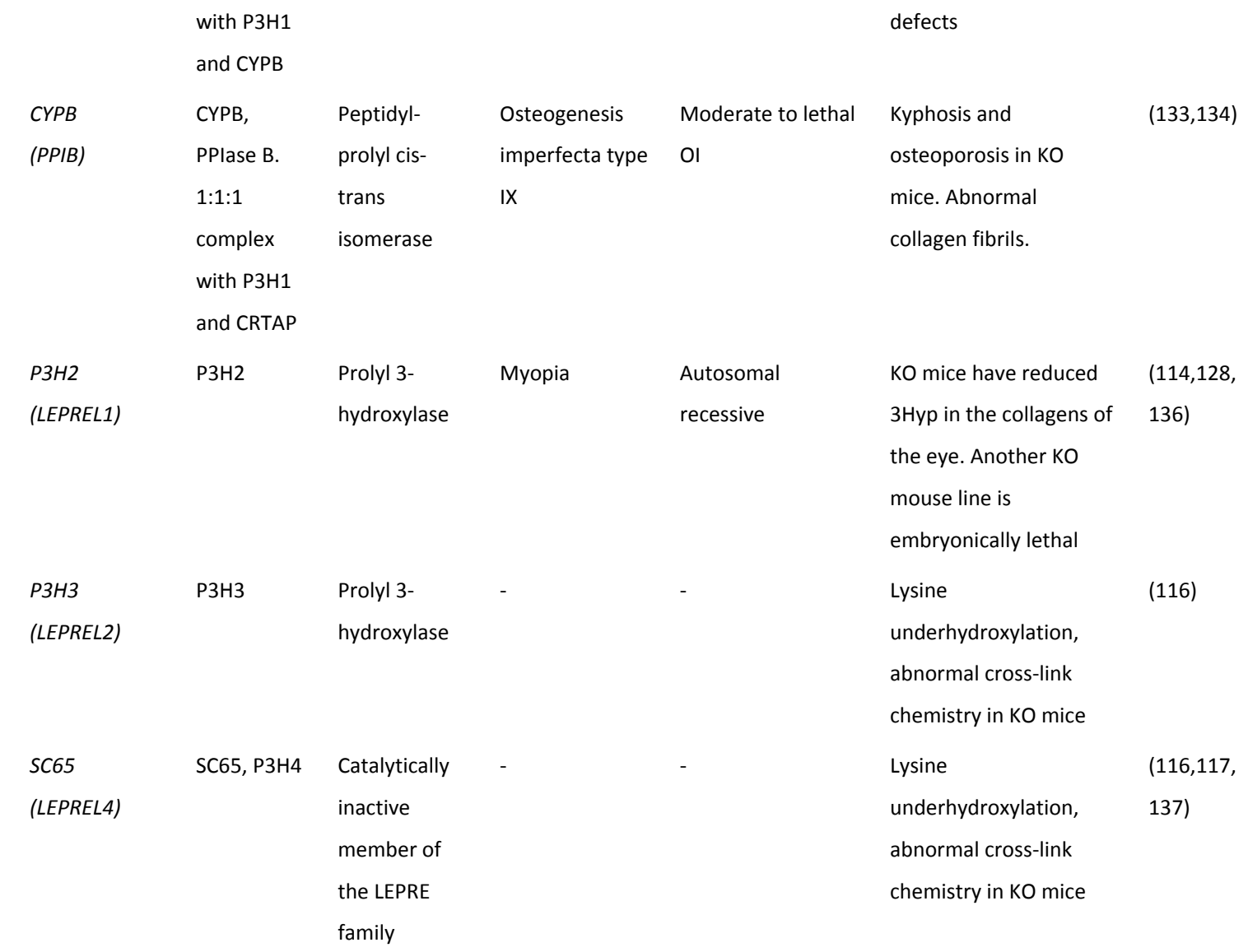

Lysyl hydroxylation and hydroxylysine glycosylation related genes, proteins and phenotypes

\begin{tabular}{|c|c|c|c|c|c|c|}
\hline PLOD1 & LH1 & $\begin{array}{l}\text { Lysyl } \\
\text { hydroxylase }\end{array}$ & $\begin{array}{l}\text { Kyphoscoliotic } \\
\text { Ehlers-Danlos } \\
\text { syndrome }\end{array}$ & $\begin{array}{l}\text { autosomal } \\
\text { recessive } \\
\text { generalized } \\
\text { connective tissue } \\
\text { disorder }\end{array}$ & $\begin{array}{l}\text { KOs have some features } \\
\text { of kEDS }\end{array}$ & $(138,176)$ \\
\hline FKBP14 & FKBP22 & $\begin{array}{l}\text { PPlase, } \\
\text { potential } \\
\text { chaperone }\end{array}$ & $\begin{array}{l}\text { Kyphoscoliotic } \\
\text { Ehlers-Danlos } \\
\text { syndrome }\end{array}$ & $\begin{array}{l}\text { Phenotypically } \\
\text { almost identical to } \\
\text { PLOD1 mutations }\end{array}$ & - & $\begin{array}{l}(175,180, \\
198)\end{array}$ \\
\hline PLOD2 & LH2 & $\begin{array}{l}\text { Lysyl } \\
\text { hydroxylase }\end{array}$ & $\begin{array}{l}\text { Bruck } \\
\text { Syndrome type } \\
2\end{array}$ & $\begin{array}{l}\text { Autosomal } \\
\text { recessive. } \\
\text { Osteogenesis } \\
\text { imperfecta with } \\
\text { joint contractures }\end{array}$ & $\begin{array}{l}\text { Early embryonic } \\
\text { lethality after } 10.5 \mathrm{dpc}\end{array}$ & $\begin{array}{l}(155,182, \\
183,190)\end{array}$ \\
\hline FKBP1O & FKBP65 & $\begin{array}{l}\text { PPlase, } \\
\text { chaperone }\end{array}$ & $\begin{array}{l}\text { Bruck } \\
\text { Syndrome type } \\
\text { 1, OI, } \\
\text { Kuskokwim } \\
\text { syndrome }\end{array}$ & $\begin{array}{l}\text { BS type } 1 \text { is } \\
\text { phenotypically } \\
\text { similar to BS type } 2\end{array}$ & $\begin{array}{l}\text { Lethality at birth, tissue } \\
\text { fragility, and growth } \\
\text { delay in KO mice. Bone } \\
\text { defects in osteoblast } \\
\text { specific KO. }\end{array}$ & $\begin{array}{l}(174,191, \\
192)\end{array}$ \\
\hline
\end{tabular}




LH, (GT), GGT.
$\begin{aligned} & \text { Lysyl } \\ & \text { tissue disorder }\end{aligned}$
hydroxylase,
collagen
glycosyltransf
erase

erase

COLGALT1

(GLT25D1)
COLGALT1

GT, Collagen

biallelic

variants

associated with

cerebral small

vessel disease
Multiple families

with similar

disease

presentation

Embryonic lethality in

(164,166,

KO mice at $9.5 \mathrm{dpc}$.

185-188)

Lethality caused by lack

of the

glycosyltransferase

activities, mutants with

intact LH activity

develop normally.

Disease linked to

Collagen IV intracellular

$(193,199)$

accumulation in $\mathrm{KO}$

mice. Skeletal and

muscular defects. 
collagen $\mathrm{P} 4 \mathrm{H}$
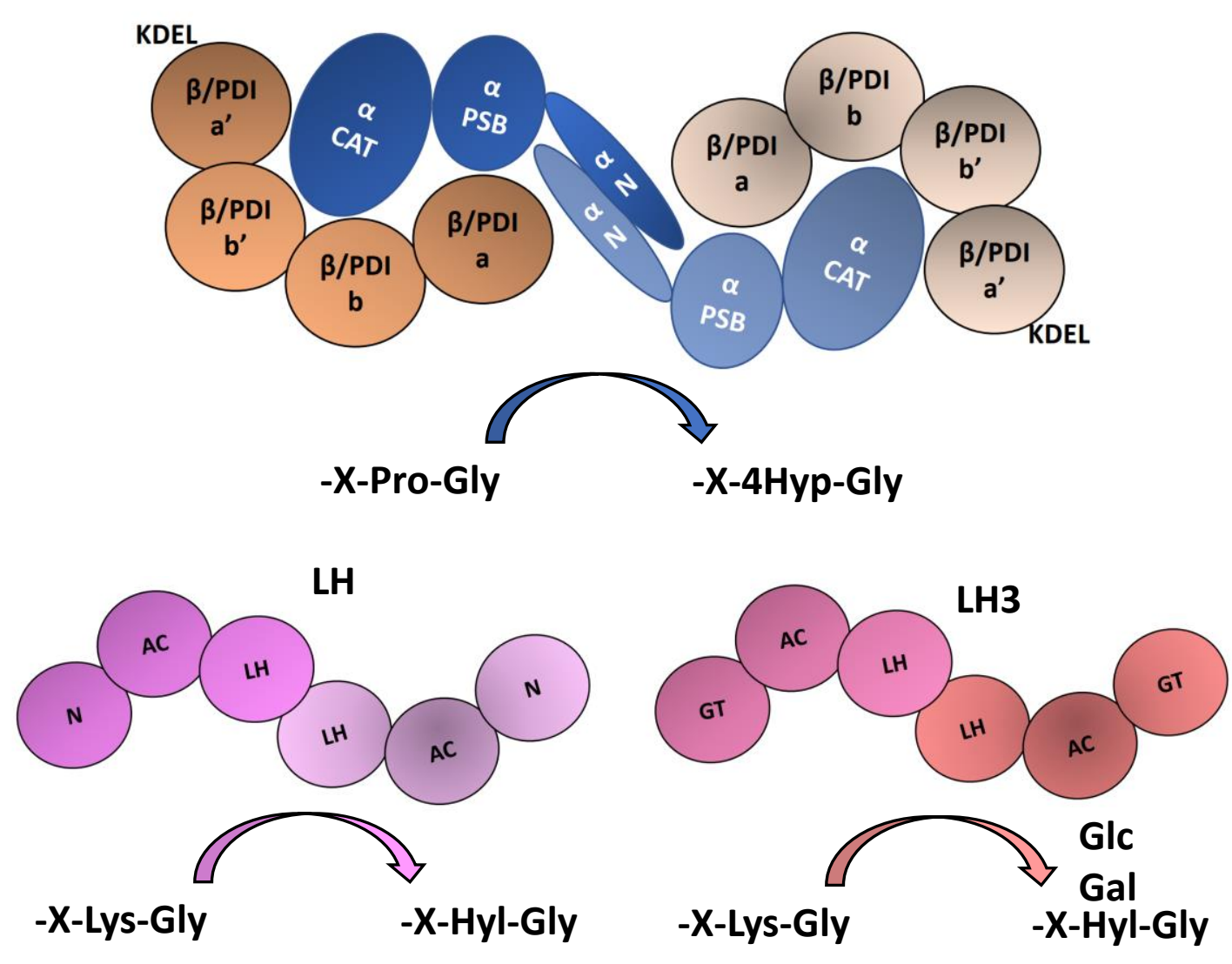

P3H1

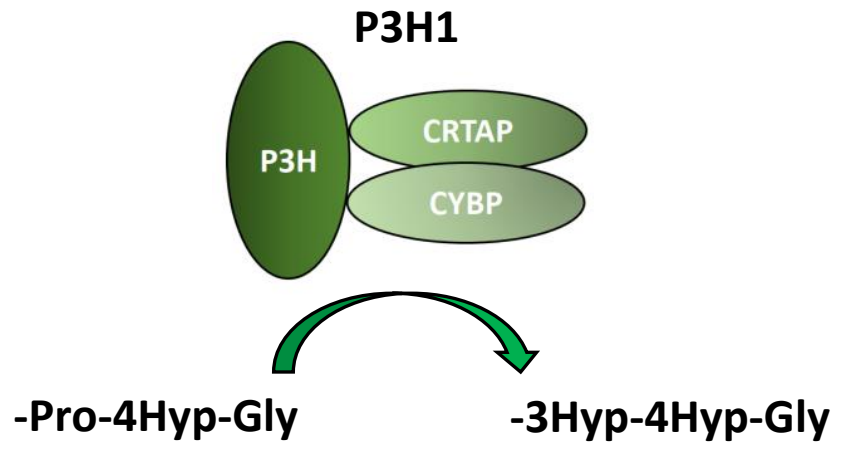


$37^{\circ} \mathrm{C}$

\section{4Нур 4Нур 4Нур 4Нур 4Нур 4Нур \\ SO00000000000000000000 P $^{\mathrm{PH}}$}
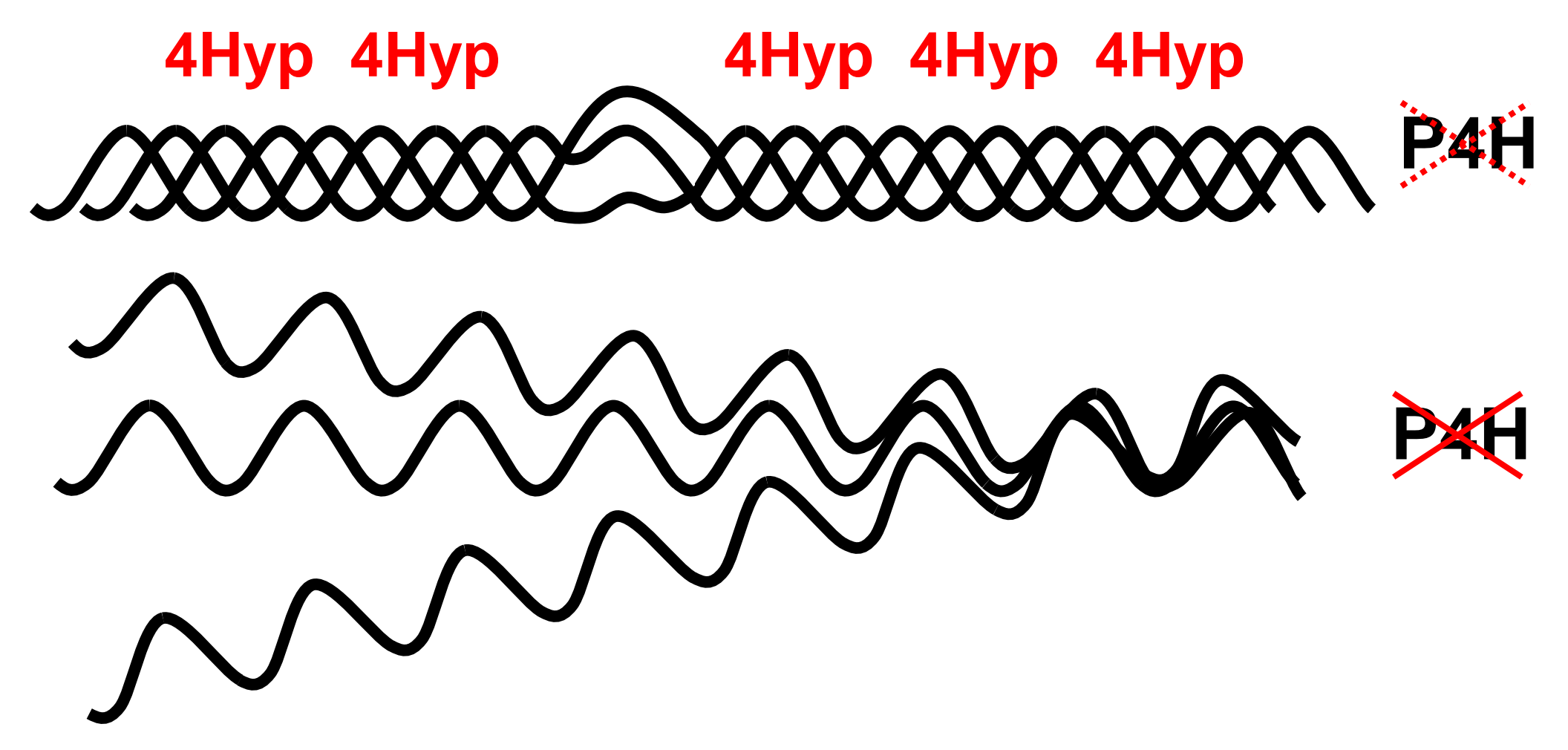
DH
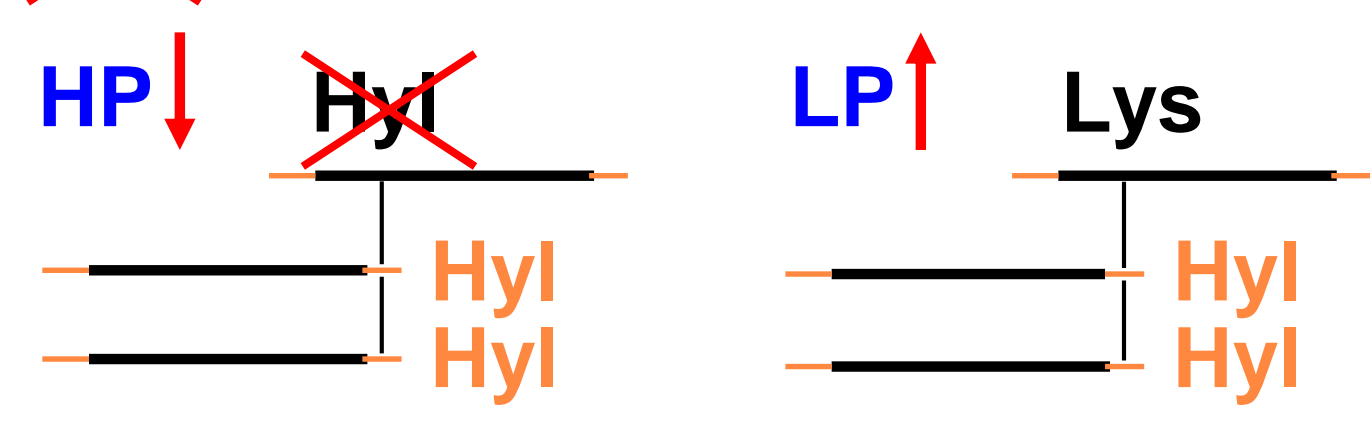

DH:
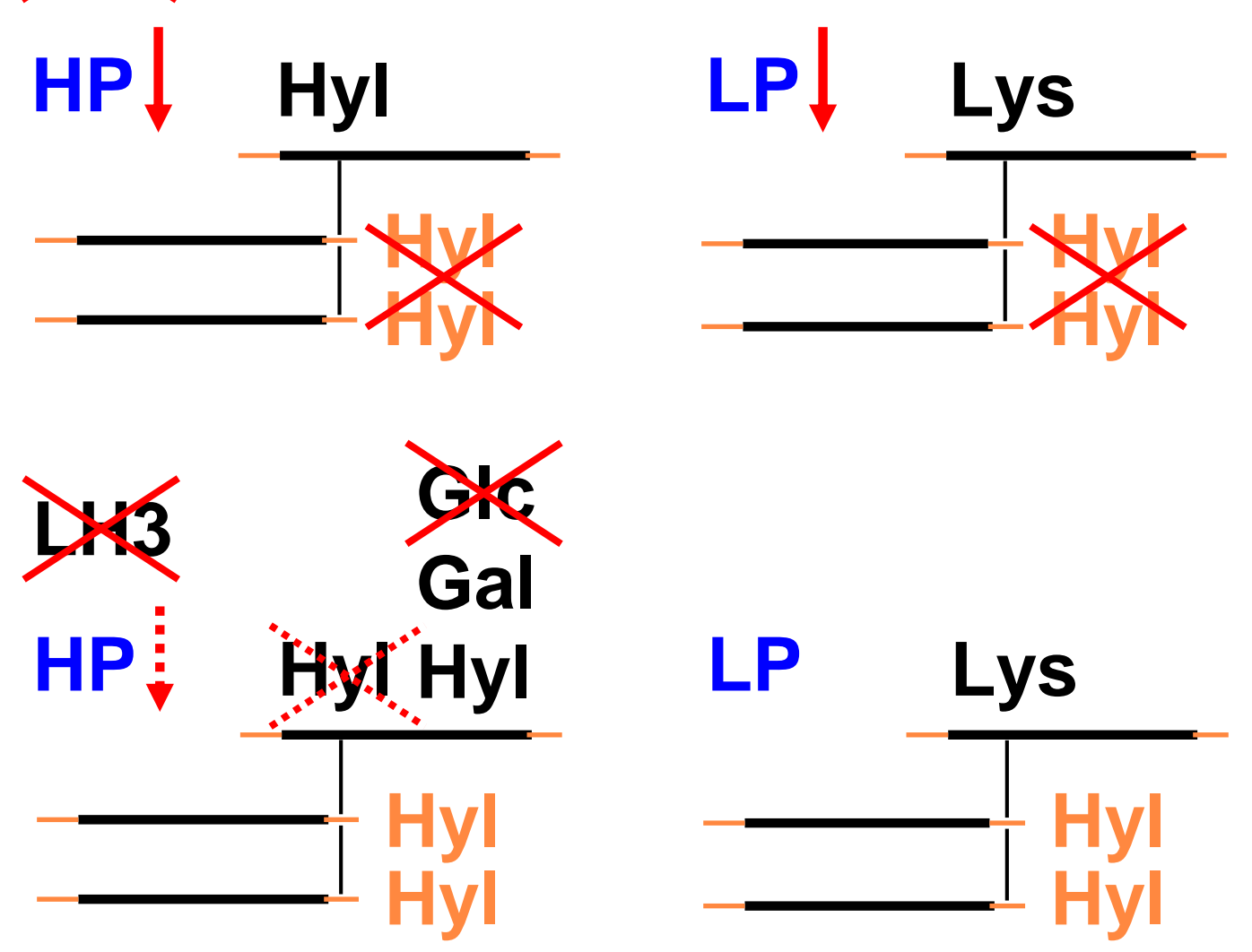